\title{
Hydrodeoxygenation of Lignin-Derived Phenols: From Fundamental Studies towards Industrial Applications
}

\author{
Päivi Mäki-Arvela and Dmitry Yu. Murzin * \\ Johan Gadolin Process Chemistry Centre, Åbo Akademi University, 20500 Turku/ ̊̊bo, Finland; \\ pmakiarv@abo.fi \\ * Correspondence: dmurzin@abo.fi
}

Received: 7 August 2017; Accepted: 22 August 2017; Published: 7 September 2017

\begin{abstract}
Hydrodeoxygenation (HDO) of bio-oils, lignin and their model compounds is summarized in this review. The main emphasis is put on elucidating the reaction network, catalyst stability and time-on-stream behavior, in order to better understand the prerequisite for industrial utilization of biomass in HDO to produce fuels and chemicals. The results have shown that more oxygenated feedstock, selection of temperature and pressure as well as presence of certain catalyst poisons or co-feed have a prominent role in the HDO of real biomass. Theoretical considerations, such as density function theory (DFT) calculations, were also considered, giving scientific background for the further development of HDO of real biomass.
\end{abstract}

Keywords: hydrodeoxygenation; bio-oil; guaiacol; lignin; heterogeneous catalyst; fuel

\section{Introduction}

Lignocellulosic biomass, which is abundant, and does not compete with the food chain, has mainly been used for production of pulp and paper via the Kraft process, in which lignin and hemicellulose have been conventionally burnt to generate energy. New transformation processes should be developed in order to utilize the above-mentioned fractions more efficiently. The research in biomass transformation to produce bio-oil via flash pyrolysis [1] and utilize different lignin fractions to produce chemicals and fuels [2,3] has been very intensive in the recent years in part due to the depleting fossil based feedstock and strive towards carbon neutral fuels and chemicals. Further transformation of these fractions, can, however, be demanding, since bio-oil is unstable, exhibiting low $\mathrm{pH}$, whereas lignin is a complex polyphenolic polymer difficult to transform selectively. One of the most important research area in transformation of bio-oil [4] and lignin [2,3] is catalytic hydrodeoxygenation (HDO) during which fuels or suitable blending agents are produced including benzene, toluene as well as cycloalkane and-ketones.

Several reviews have already been published on HDO of lignin based phenols [5-15]. In these works, the main emphasis has been on different catalysts [5-8,11], deactivation $[6,8,9]$, mechanism $[6,8,10]$, kinetics [6]. Some specific topics, such as the use of carbide catalysts [12] and production of jet fuel from lignin [7] have been recently reviewed. Bio-oil HDO including the patent literature was reviewed by Zacher et al. in 2014 [13]. The recent trends in HDO of bio-oils have been summarized since this research area is highly important and very many new studies are constantly appearing [16-64]. Although HDO of phenolic compounds has already been investigated during several decades [65,66] and was shown to be a promising method to upgrade bio-oil, it is still challenging. The main challenges are catalyst deactivation, polymerization of phenolic compounds at elevated temperatures and the use of real bio-oils which contain various compounds and catalyst poisons. 
In this review, the main emphasis is in depth elucidation of the reaction network in hydrodeoxygenation of phenolic model compounds, especially focusing on which types of model molecules have been used for HDO and comparison of their reactivity. The experimental data will be correlated with the theoretical results using density functional theory and bond dissociation energies for different functional groups. In addition, to bring the HDO process closer to industry, several relevant aspects, such as catalyst deactivation, recycling and reuse have to be properly addressed. Typically, in continuous HDO of phenolic compounds deactivation of catalyst is significant, therefore relevant literature has been described. It is also of utmost importance for industrial processes to know exactly the mass balances and in particular formation of various undesired side products including gaseous ones and coke.

The aim in this review is to report the main trends in the HDO of lignin derived model molecules, bio-oil and lignin per se. Special attention was put on the effect of temperature, pressure, metal and support selection. In addition, a reaction network during the HDO of model molecules will be discussed and reactivity of different model molecules in a single feed studies over the same catalyst will be compared. Continuous operation, catalyst reuse and deactivation will also be discussed in depth in order to relate the current state-of-art more closely to industrial applicability.

\section{Bio-Oil and Lignin Properties and Need for Upgrading}

\subsection{Bio-Oil Properties}

Bio-oil is a product, which is most commonly produced via fast pyrolysis, in which the biomass is treated in the temperature range of $300-600{ }^{\circ} \mathrm{C}$ and short residence time from $1 \mathrm{~s}$ to $2 \mathrm{~s}$ [15]. In this process biomass is deconstructed giving char as well as liquid, gases. The liquid fraction called bio-oil contains typically a large amount of water, varying in the range of $10-30 \mathrm{wt} \%$, and different chemicals including aldehydes, acids, carbohydrates, phenolics, ketones, alcohols, etc. [15,67]. The composition of bio-oil varies significantly depending on the raw material. Bio-oils being typically non-stable, have a high viscosity, acidity $(\mathrm{pH}=2.8-3.8)$ and low energy content or heating value due to high oxygen content $[47,64]$. Typically, bio-oils can contain up to $40 \mathrm{wt} \%$ oxygen [15], requiring upgrading during which different reactions occur, such as cracking, decarbonylation decarboxylation, hydrogenation, hydrocracking and hydrodeoxygenation. The main aim in hydrodeoxygenation is to reduce the oxygen content in bio-oil, especially present in aromatic hydroxyl and methoxy containing molecules. The HDO reactions of these molecules (e.g., guaiacol), are, however, challenging due to their low stability which causes catalyst deactivation [48].

\subsection{Structure of Different Lignin Types}

Properties of Organosolv, Kraft and Soda Lignin

Organosolv lignin can be prepared under mild extraction conditions using different solvents, such as an ethanol/water mixture at $200^{\circ} \mathrm{C}$ [68]. Sulfur-free organosolv lignin suitable for catalytic transformation [69] has a lower average molecular weight compared to other lignin [1]. The organosolv lignin utilized by Kasakov et al. exhibited seven interconnected monolignols in its structure [2]. On the other hand, kraft and soda lignin is more condensed [1]. This can be explained by the preparation method involving alkaline reactions, including degradation of aryl-ethyl bonds and condensation because of carbanions addition to quinine methide during precipitation [1].

\section{HDO of Lignin-Derived Model Compounds, Simulated and Real Bio-Oil and Lignin}

In the HDO of bio-oil the main target is to decrease the oxygen content of the product and to improve the product heating value. It has been reported that the heating value of, for example, wheat based bio-oil is $21.2 \mathrm{MJ} / \mathrm{kg}$ on the dry basis [35] while the corresponding value for yellow poplar based bio-oil is $17.3 \mathrm{MJ} / \mathrm{kg}$ dry basis [4]. In the latter work the heating value of the processed 
bio-oil was increased maximally to $22.8 \mathrm{MJ} / \mathrm{kg}$ over Ni/SBA- 15 catalyst during $\mathrm{HDO}$ at $300{ }^{\circ} \mathrm{C}$ under 30 bar hydrogen being $24 \%$ better than in the feed. Furthermore, van Krevelan plot showing the $\mathrm{H} / \mathrm{O}$ and $\mathrm{O} / \mathrm{C}$ molar ratio of different products gives an idea of how HDO decreases oxygen content during the process (Figure 1). For example, when the light oil fraction in wheat based pyrolysis oil containing $57 \%$ water was hydrodeoxygenated with different catalysts at $250{ }^{\circ} \mathrm{C}$ under 80 bar hydrogen, its molar $\mathrm{O} / \mathrm{C}$ ratio decreased to 0.22 using $\mathrm{Ni} / \mathrm{ZrO}_{2}$ as a catalyst. In another study with bio-oil from yellow poplar the $\mathrm{O} / \mathrm{C}$ ratio was decreased from 0.8 to 0.2 using $\mathrm{Pt} / \mathrm{C}$ as a catalyst [4]. When considering the fuel properties after HDO, it should be kept in mind that even cyclohexanol, cyclohexanone and cyclohexane are valuable products which can be blended with petroleum [70]. Furthermore, for example, cyclohexane, toluene and xylene exhibit suitable vapor pressures and carbon number to be used in gasoline [62].

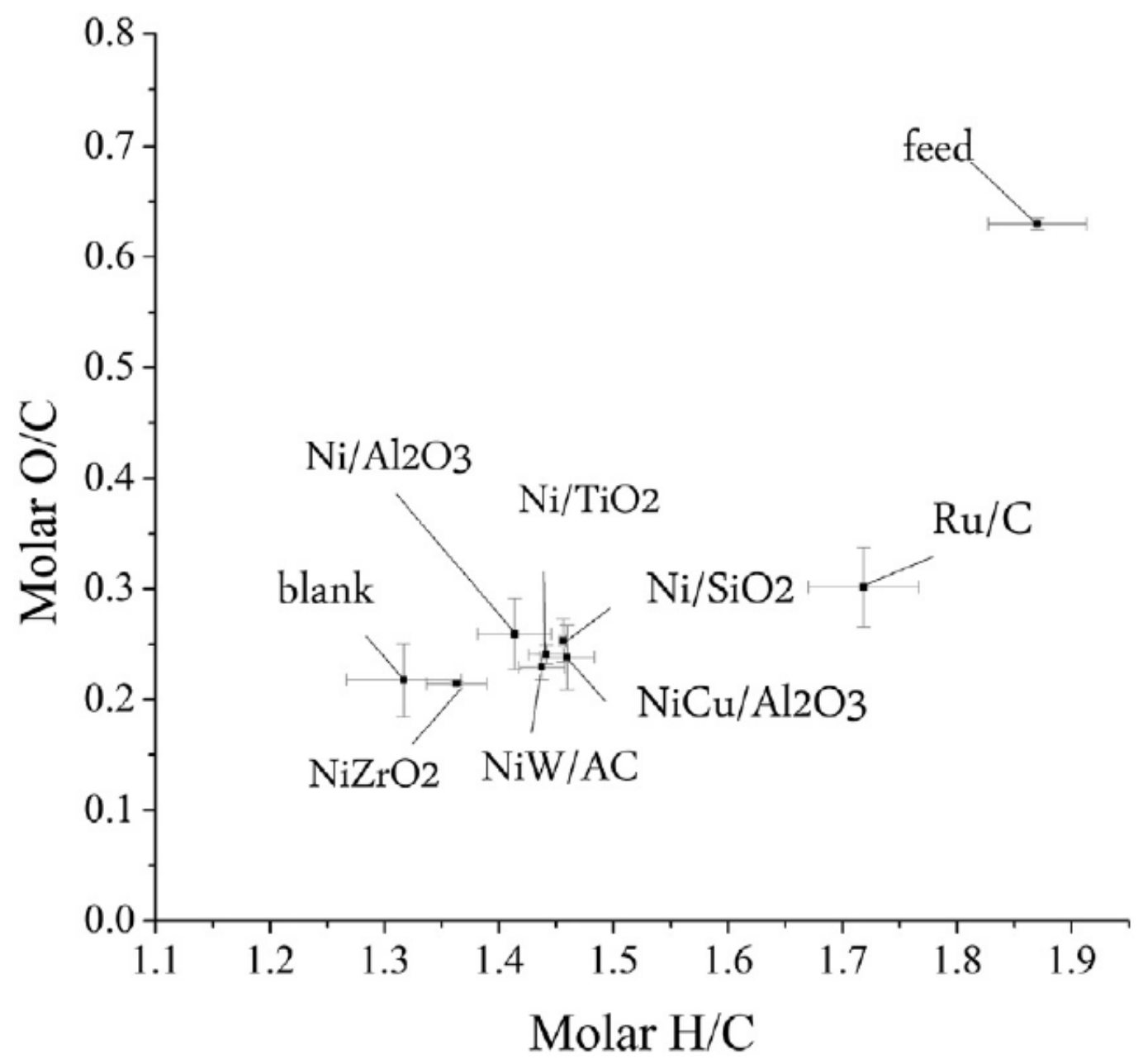

Figure 1. Van Krevelan plot of the light phase of pyrolysis oil prepared from wheat straw and its upgraded products using different catalysts at $250{ }^{\circ} \mathrm{C}$ under 80 bar hydrogen [35].

In the recent review [7] results from HDO of model molecules, simulated and real bio-oils and lignin were summarized. Model molecules have been selected among the three phenols derived from lignin, namely p-coumaryl alcohol, coniferyl alcohol and sinapyl alcohol (Figure 2). The main emphasis has been put on reactivity of different molecules, the proposed reaction pathways and thermodynamics of different reactions. 
<smiles>OC/C=C/c1ccc(O)cc1</smiles><smiles>COc1cc(/C=C/CO)ccc1O</smiles>

Figure 2. The main phenols from lignin adapted from reference [7].

\subsection{Conversion and Main Products in the HDO of Lignin-Derived Model Molecules}

Conversion values and the main products in HDO of lignin derived model molecules are shown in Tables 1 and 2 and Figure 3. For guaiacol, which is one OF the most studied model molecule, containing both methoxy and hydroxyl group, it is possible to obtain complete conversion under either high temperatures [50] or at slightly lower temperatures under high hydrogen pressure (Table 1, entry 1) [46]. However, in most of the cases lower conversion levels have been obtained [26,33,38,58]. Complete deoxygenation for guaiacol is also difficult, since these yields vary between $10-75 \%$, except for a high $\mathrm{HDO}$ yield with cyclohexane as the main product obtained over $\mathrm{Ni} / \mathrm{SiO}_{2}-\mathrm{ZrO} \mathrm{O}_{2}$ at $300{ }^{\circ} \mathrm{C}$ under 50 bar (Figure 3). When, however, the methoxy group is in position 3, HDO is easier, most probably due to less steric hindrance (Table 1, entry 2). The reasons for this difficulty to deoxygenate guaiacol and other model molecules are discussed in Section 3.3.

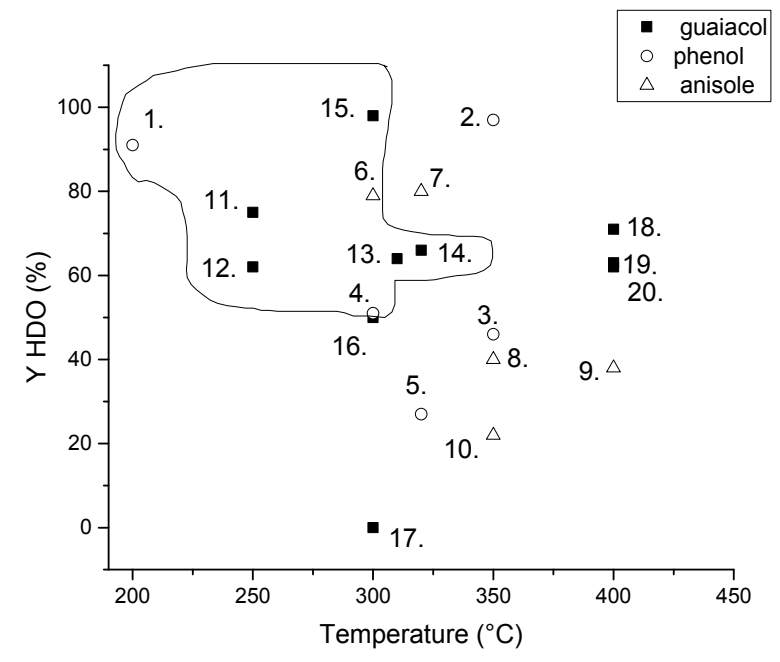

Figure 3. Hydrodeoxygenation (HDO) yield in phenol, anisole and guaiacol HDO over different catalysts as a function of temperature. Notation: For phenol 1. CoNx, 20 bar, cyclohexane [63], 2. $\mathrm{MoO}_{3} / \mathrm{ZrO}_{2}, 60$ bar, benzene [39], 3. $\mathrm{MoO}_{3} / \mathrm{ZrO}_{2}, 60$ bar, benzene [39], 4. ReOx/CNFox, 50 bar, cyclohexane [37], 5. $\mathrm{MoO}_{3}, 1$ bar, benzene [36], for anisole 6. ReOx/CNFox, 50 bar, cyclohexane [37], 7. $\mathrm{MoO}_{3}, 1$ bar, benzene [36], 8. $\mathrm{MoO}_{3} / \mathrm{ZrO}_{2}, 60$ bar, benzene [39], 9. Pt-Sn/CNF/Inconel, 1 bar, benzene [48], 10. Ni-catalyst, 1.7 bar, benzene [50], for guaiacol: 11. Pt/Alumina silicate, 30 bar, cyclohexane [49], 12. $\mathrm{Ni} / \mathrm{ZrO}_{2}, 100$ bar, main product cyclohexanol S $=50 \%$, cyclohexane $\mathrm{S}=25 \%$ [47], 13. $\mathrm{Rh} / \mathrm{ZrO}_{2}$ +aluminosilicate, 40 bar, cyclohexane [45], 14. $\mathrm{MoO}_{3}, 1$ bar, cyclohexane, [36], 15. Ni/SiO $2-\mathrm{ZrO}_{2}, 50$ bar, cyclohexane [62], 16. CoMoS, 40 bar, benzene main product [46], 17. $\mathrm{Mo}_{2} \mathrm{~N}$, 50 bar, no HDO [58], 18. Fe/ $\mathrm{SiO}_{2}, 1$ bar, benzene and toluene [33], 19. Pt-Sn/CNF/Inconel, 1 bar, toluene [48], 20. Ni-catalyst, 1.7 bar, benzene and toluene [50]. Notation: Inside the area surrounded by the curve, the main products are cycloalkanes. 
Table 1. Single model molecule feed HDO results. Notation: $\mathrm{Y}$ denotes yield and S selectivity. $\mathrm{X}$ is conversion.

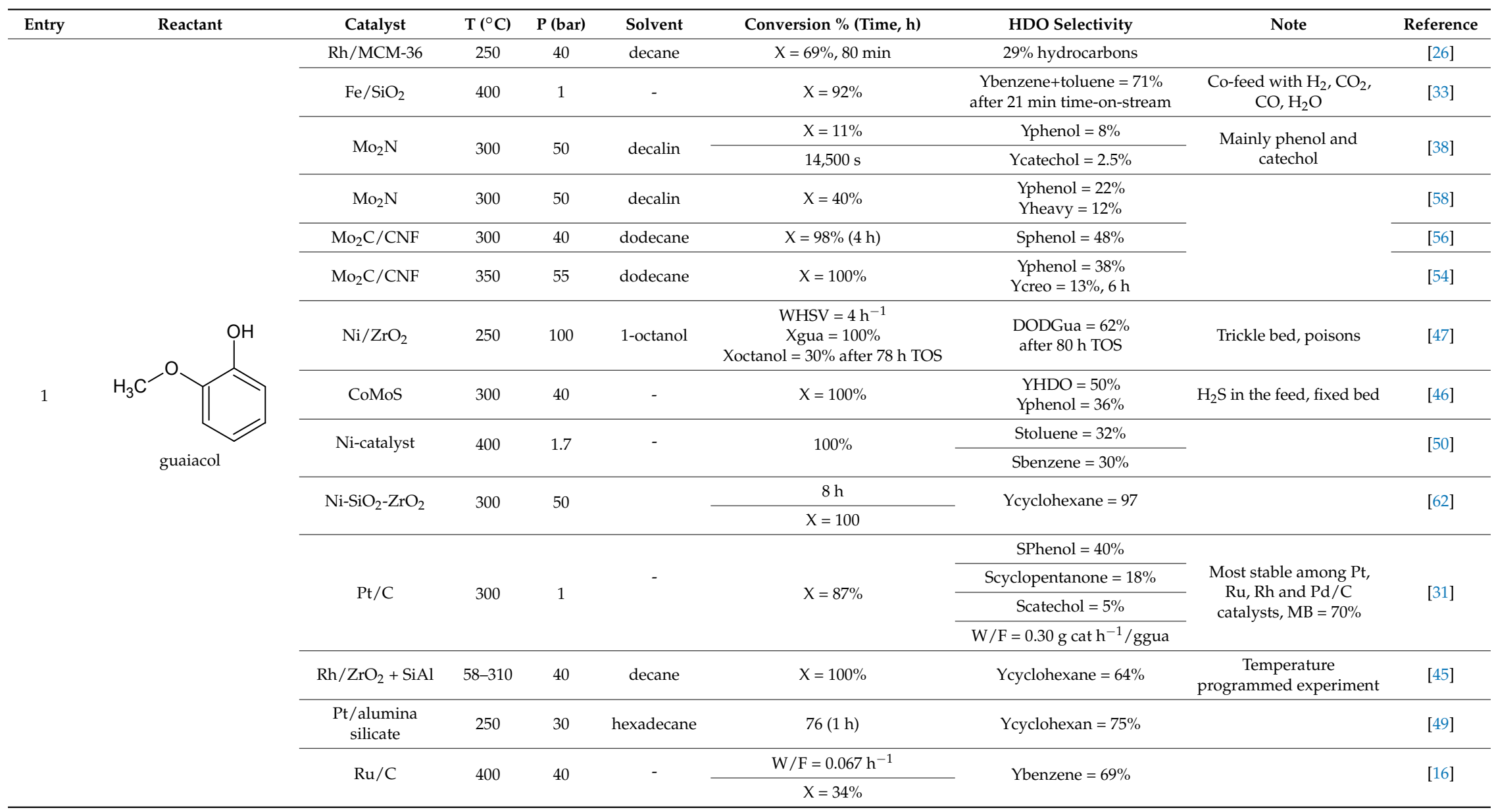


Table 1. Cont.

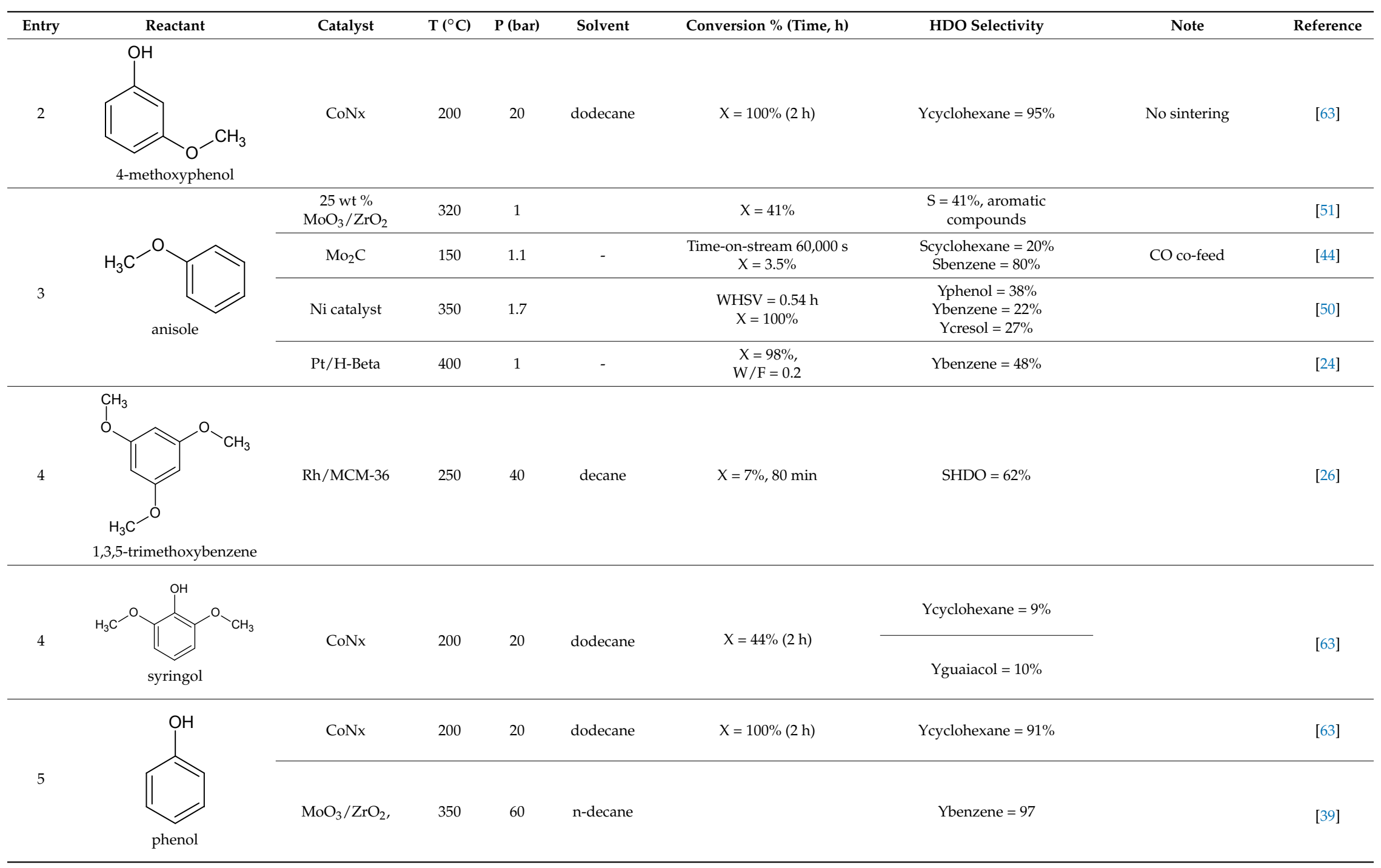


Table 1. Cont

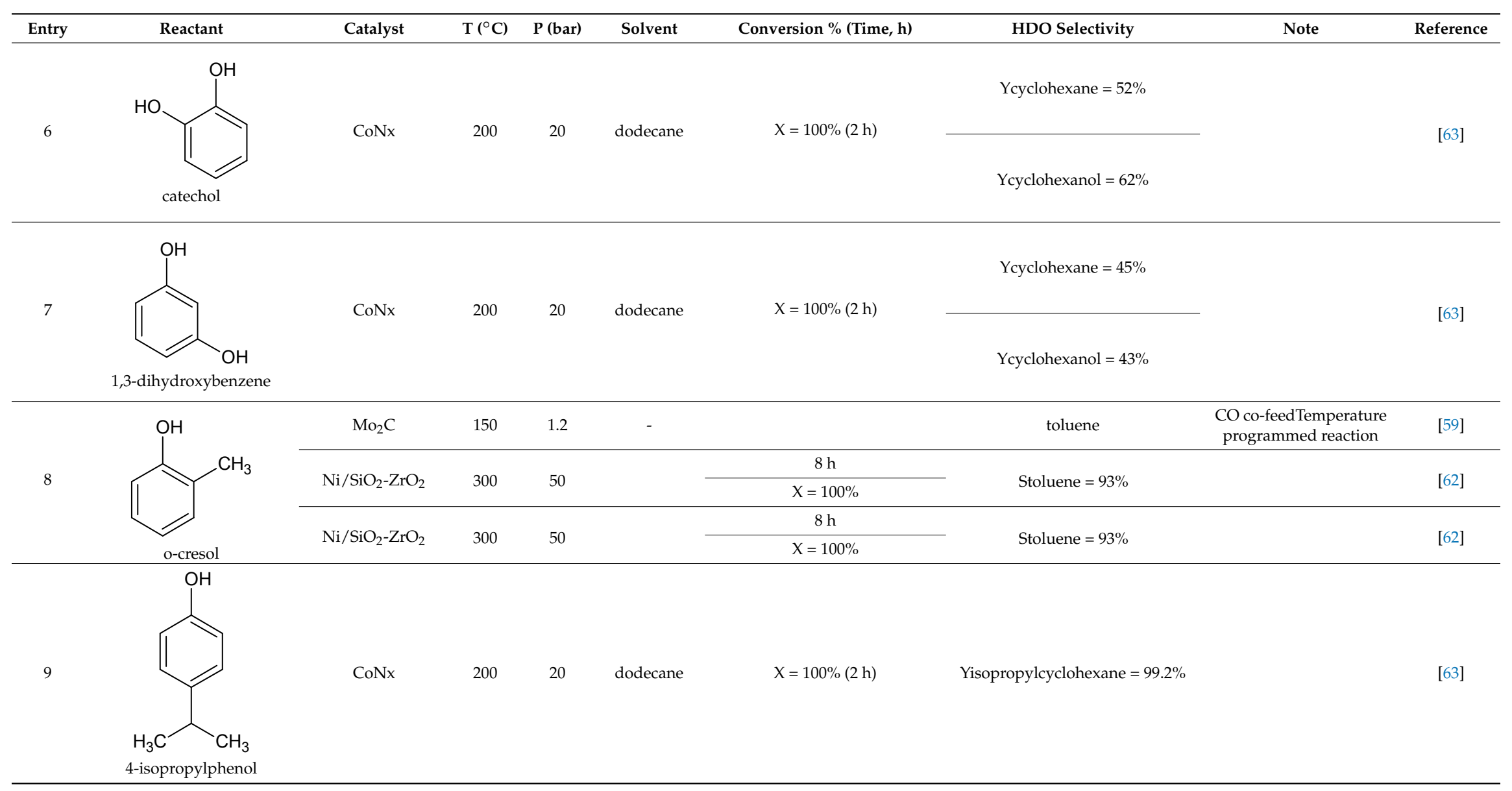


Table 1. Cont

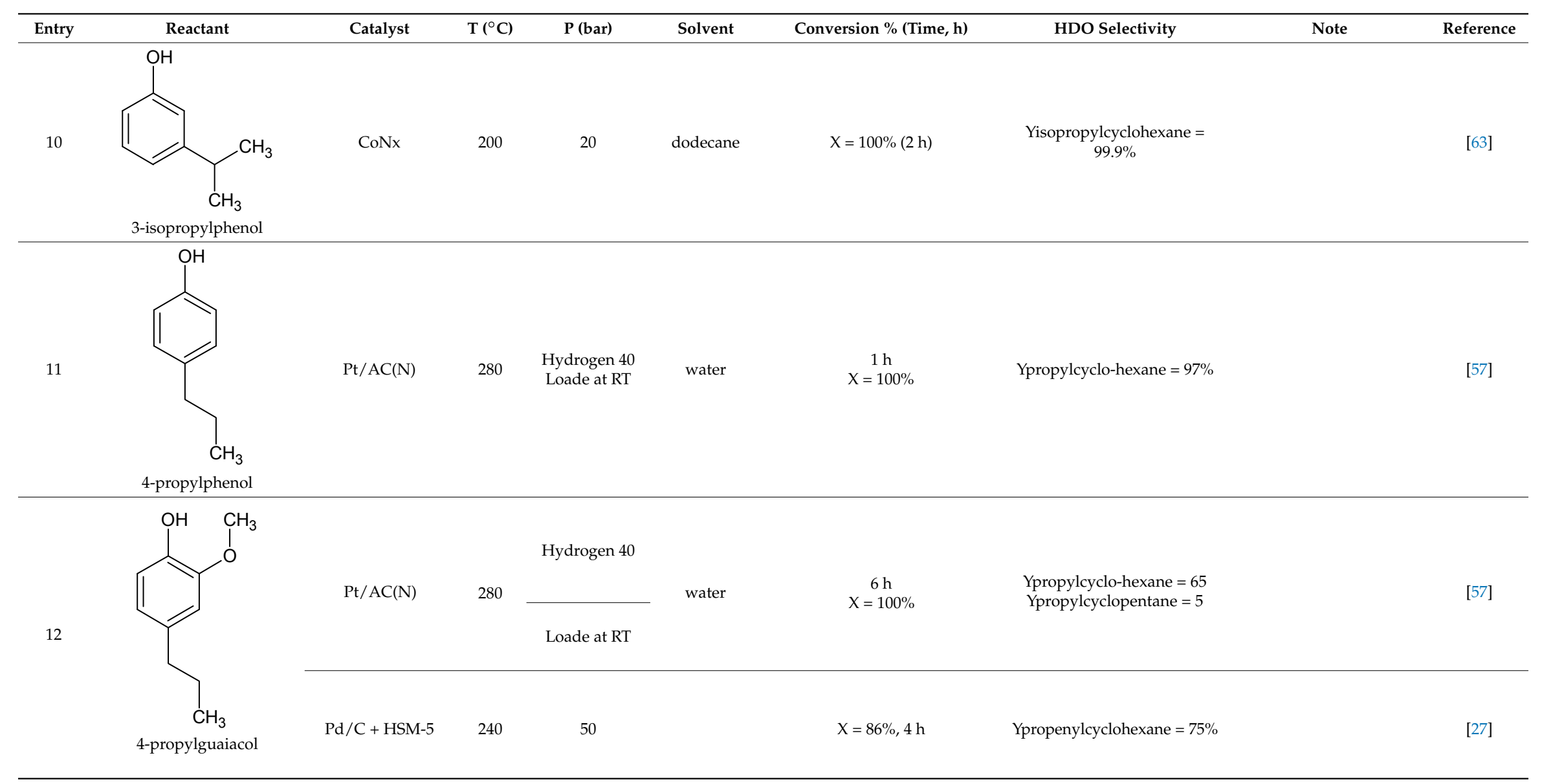


Table 1. Cont

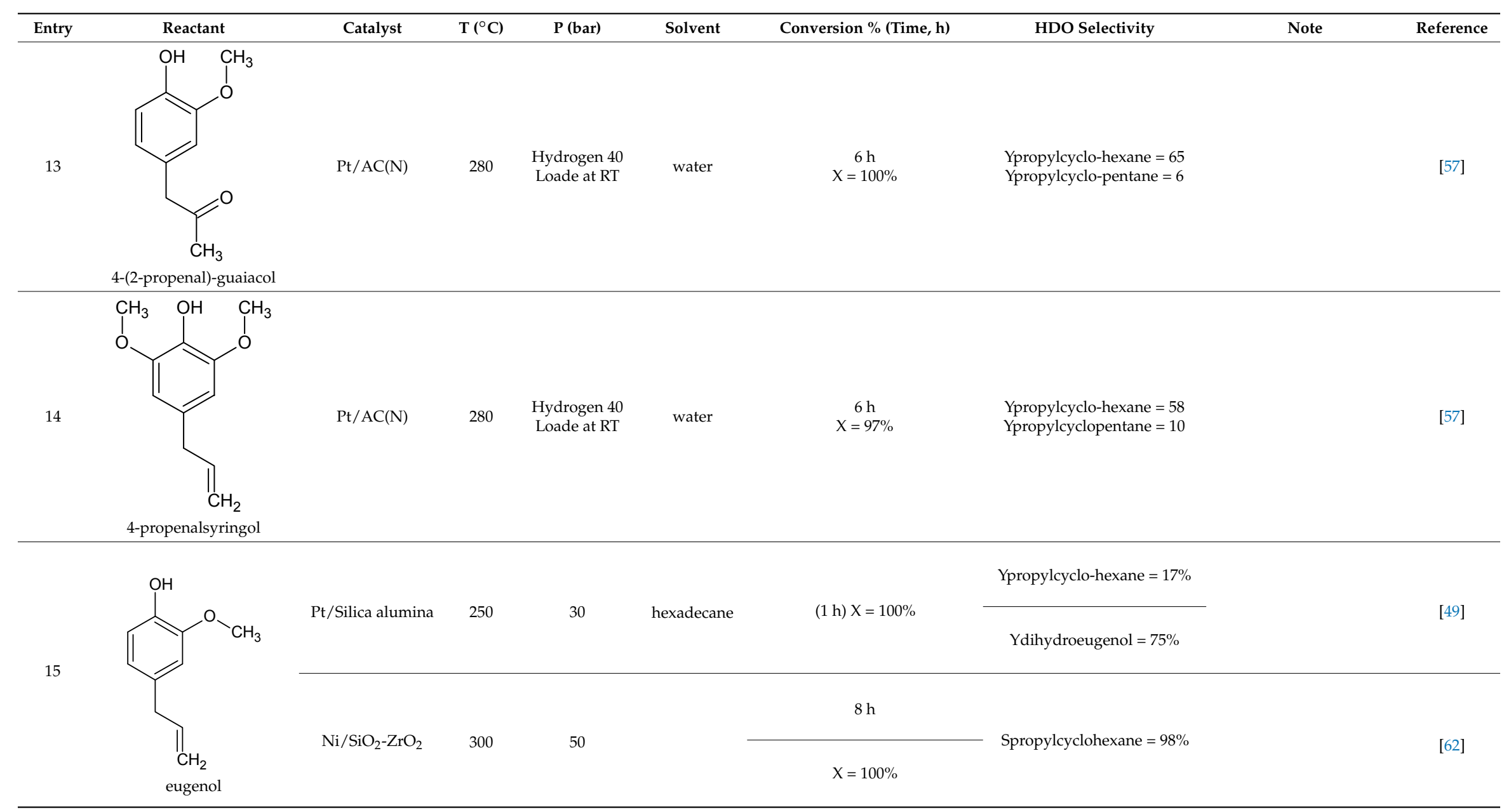


Table 1. Cont.

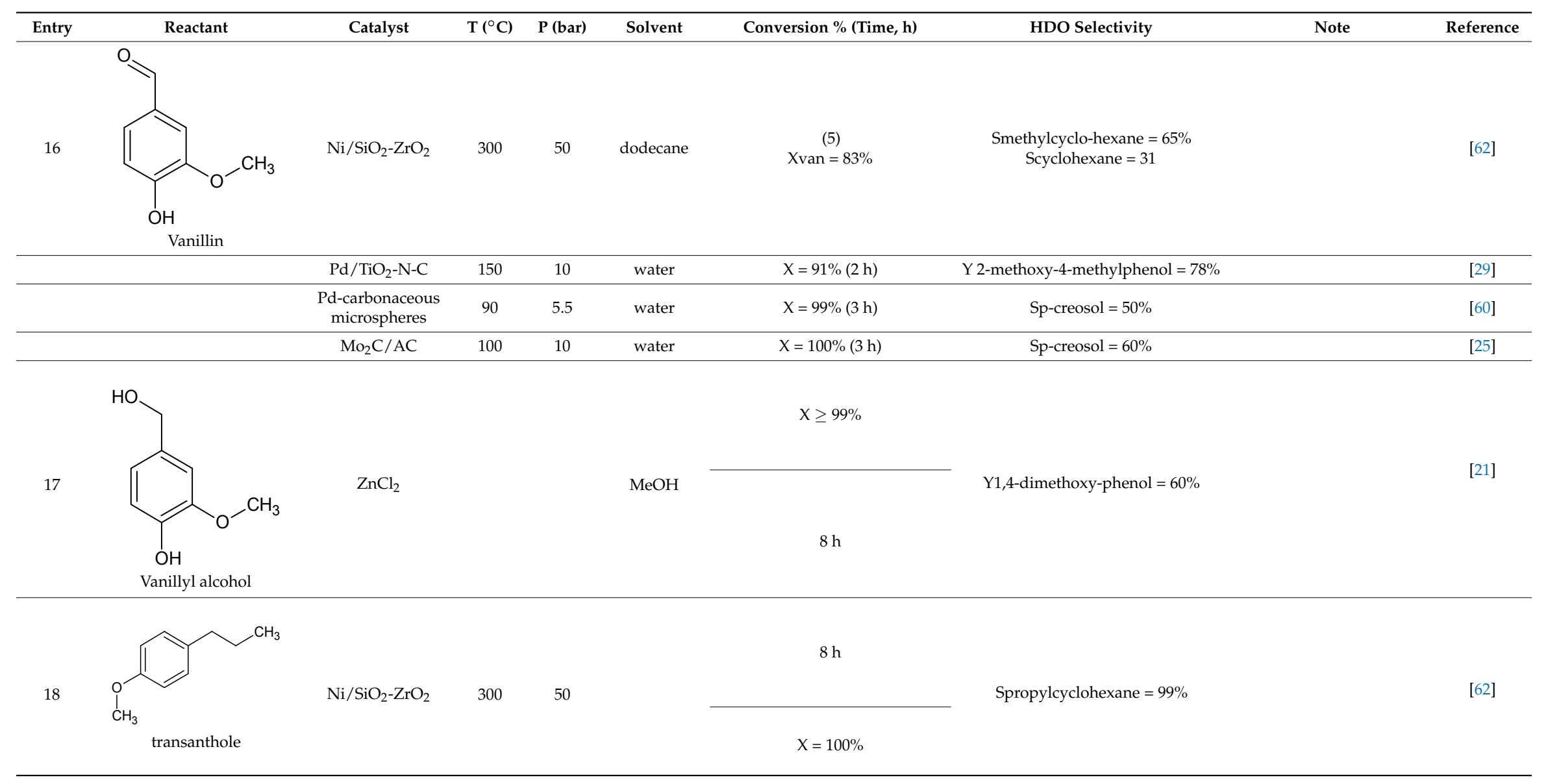


Table 1. Cont.

\begin{tabular}{|c|c|c|c|c|c|c|c|c|c|}
\hline Entry & Reactant & Catalyst & $\mathrm{T}\left({ }^{\circ} \mathrm{C}\right)$ & P (bar) & Solvent & Conversion \% (Time, h) & HDO Selectivity & Note & Reference \\
\hline 19 & & $\mathrm{Pt} / \mathrm{Al}_{2} \mathrm{O}_{3}$ & 325 & 5 & & $\begin{array}{c}\mathrm{X}=75 \% \\
\mathrm{~W} / \mathrm{F}=1 \mathrm{~kg} \text { cat.s } / \mathrm{mol}\end{array}$ & $\begin{array}{c}\text { Sphenol }=87 \% \\
\text { Sbenzene }=20 \%\end{array}$ & $\mathrm{H}_{2} / \mathrm{O}=23$ & {$[61]$} \\
\hline 20 & & CoNx & 200 & 20 & dodecane & $x=100 \%$ & Ycyclohexane $=92 \%$ & & [63] \\
\hline 21 & ether & $\mathrm{CoNx}$ & 200 & 20 & dodecane & $C=100 \%$ & Ycyclohexane $=99.9 \%$ & & [63] \\
\hline 22 & $\begin{array}{l}\mathrm{CH}_{3} \\
\text { dimer }\end{array}$ & $\mathrm{Zn} / \mathrm{Pd} / \mathrm{C}$ & 150 & 21 & $\mathrm{MeOH}$ & $\begin{array}{c}2 \mathrm{~h} \\
x=100 \%\end{array}$ & $\begin{array}{c}\text { Y2-methoxy-4-propylphenol } \\
=85 \% \\
\text { Yguaiacol }=85 \%\end{array}$ & & [21] \\
\hline
\end{tabular}


Table 2. Comparative single feed HDO results using one catalyst. Notation: $\mathrm{Yi}, \mathrm{j}$ is yield in which i is the reactant and $\mathrm{j}$ product, $\mathrm{X}$ denotes conversion and $\mathrm{S}$ selectivity.

\begin{tabular}{|c|c|c|c|c|c|c|c|c|}
\hline $\begin{array}{c}\text { Comparison of the } \\
\text { Reactivity }\end{array}$ & Catalyst & $\mathrm{T}\left({ }^{\circ} \mathrm{C}\right)$ & $\mathbf{P}($ bar) & Solvent & $\begin{array}{l}\text { Conversion \% } \\
\text { (Time, h) }\end{array}$ & Products & Notation & Reference \\
\hline $\begin{array}{l}\text { Phenol, anisole, } \\
\text { guaiacol }\end{array}$ & $\mathrm{MoO}_{3} / \mathrm{ZrO}_{2}$ & 350 & 60 & & $\begin{array}{c}\text { Xphe }=48 \% \\
\text { Xanisole }=55 \% \\
\text { Xgua }=51 \%\end{array}$ & $\begin{array}{c}\text { Yphe, benzene }=46 \% \\
\text { Yani, benzene }=40 \% \\
\text { Ygua, phe }=23 \%\end{array}$ & Trickle bed & [39] \\
\hline $\begin{array}{l}\text { Phenol, cresol, } \\
\text { anisole, guaiacol, } \\
\text { diphenyl ether }\end{array}$ & $\mathrm{MoO}_{3}$ & 320 & 1 & - & $\begin{array}{c}\text { Xphe }=29 \% \\
\text { Xani }=79 \% \\
\text { Xgua }=74 \% \\
\text { Xcre }=49 \% \\
\text { Xdip }=83 \%\end{array}$ & $\begin{array}{c}\text { Yphe, benzene }=44 \% \\
\text { Yani, benzene }=31 \% \\
\text { Ygua, phenol }=31 \% \\
\text { Ycre, toluene }=49 \% \\
\text { Ydip, benzene }=72 \%\end{array}$ & $\begin{array}{l}\text { With phenol the } \\
\text { solvent is } \\
\text { mesitylene }\end{array}$ & [36] \\
\hline $\begin{array}{l}\text { Guaiacol, anisole, } \\
\text { phenol, o-cresol }\end{array}$ & $10 \mathrm{ReO}_{x} / \mathrm{CNF}$ ox & 300 & 50 & dodecane & $\begin{array}{c}(4 \mathrm{~h}) \\
\text { Xphe }=90 \% \\
\text { Xanisole }=100 \% \\
\text { Xgua }=100 \% \\
\text { Xcre }=44 \%\end{array}$ & $\begin{array}{c}\text { Yphe, cyclohexane }=51 \% \\
\text { Ygua, cyclohexane }=65 \% \\
\text { Yani, cyclohexane }=79 \% \\
\text { Ycre, methylcyclohexane }=18 \% \\
\text { Ycre, toluene }=16 \%\end{array}$ & & {$[37]$} \\
\hline $\begin{array}{c}\text { Anisole, } \\
\text { phenylacetate }\end{array}$ & $\mathrm{Pt} / \mathrm{Al}_{2} \mathrm{O}_{3}$ & 325 & 5 & & $\begin{array}{c}50 \mathrm{~h} \\
\text { time-on-stream } \\
\text { Xani }=50 \% \\
\text { Xpheac }=58 \%\end{array}$ & $\begin{array}{c}\text { Spheac, benzylalcohol = } 83 \% \\
\text { Spheac, benzene }=16 \% \\
\text { Sani, benzylalcohol }=55 \% \\
\text { Sani, benzene }=12\end{array}$ & $\mathrm{H}_{2} / \mathrm{O}=23.2$ & {$[61]$} \\
\hline Anisole, guaiacol & $\mathrm{Pt}-\mathrm{Sn} / \mathrm{CNF} /$ Inconel & 400 & 1 & & $\begin{array}{c}125 \text { min TOS } \\
\mathrm{W} / \mathrm{F}=2 \mathrm{~g} \text { cat } / \mathrm{g} \\
\text { react } \mathrm{h}^{-1} \\
\text { Xgua }=97 \% \\
\text { Xani }=67 \%\end{array}$ & $\begin{array}{l}\mathrm{Y} \text { gua, toluene }=63 \% \\
\mathrm{Y} \text { ani, benzene }=38 \%\end{array}$ & & [48] \\
\hline
\end{tabular}


For methoxylated benzenes, such as anisole, and trimethoxybenzene (Table 1, entries 3 and 4), it is easier to achieve HDO compared to guaiacol. For example, selectivity to anisole HDO products was $100 \%$ at relatively mild temperature of $150{ }^{\circ} \mathrm{C}$ under atmospheric pressure over $\mathrm{Mo}_{2} \mathrm{C}$ catalyst (Table 3, entry 3) [44].

Table 3. Homolytic bond dissociation energies for lignin derived model molecules calculated by B3LYP / 6-311 G $(\mathrm{d}, \mathrm{p})$ level theory at $320^{\circ} \mathrm{C}$ in the gas phase adapted from reference [36] and comparison with other bond dissociation energies from the literature. Bond dissociation energies are given in $\mathrm{kJ} / \mathrm{mol}$.

\begin{tabular}{cccccccc}
\hline Bond & & & & & \\
& & & & & & \\
$\mathrm{Ph}-\mathrm{OH}$ & 472 & 481 & 469 & 469 & - & - & - \\
$\mathrm{Ph}-\mathrm{OCH} \mathrm{H}_{3}$ & 384 & 397 & - & - & 384 & - & - \\
$\mathrm{Ph}-\mathrm{O}-\mathrm{CH}_{3}$ & 218 & 205 & - & - & 238 & - & - \\
$\mathrm{Ph}-\mathrm{OPh}$ & - & - & - & - & & 280 & - \\
aliphatic C-O & - & - & - & - & & & $339[43]$ \\
\hline
\end{tabular}

Phenol HDO is also giving high conversions and high yields of cyclohexane at moderate temperatures under relatively high hydrogen pressures (Table 1, entry 5) [63]. On the other hand, dihydroxylated catechol was more difficult to deoxygenate compared to phenol, since this molecule exhibited sterical restrictions and strong adsorption containing two hydroxyl groups in the vicinity of each other (see Section 3.5.5). It was also observed that when the other hydroxyl was in the meta position, degree of HDO was much higher (Table 1, entry 7). The products in the HDO of guaiacol, phenol and anisole are mainly aromatic compounds, such as benzene and toluene at high temperatures, whereas cyclohexane can be formed below $340^{\circ} \mathrm{C}$ over catalysts exhibiting hydrogenation activity, such as supported $\mathrm{Ni}, \mathrm{Rh}, \mathrm{ReOx}, \mathrm{CoNx}$ and $\mathrm{MoO}_{3}[36,37,43,62,63]$.

Monooxygenated o-cresol with a methyl group in ortho position is easy to deoxygenate (Table 1 , entry 8) [62]. For molecules containing three oxygenated groups, such as vanillin, maximally only $65 \%$ selectivity towards methylcyclohexane was obtained at $300{ }^{\circ} \mathrm{C}$ under 50 bar over $\mathrm{Ni} / \mathrm{SiO}_{2}-\mathrm{ZrO}$ catalyst [62].

The propyl substituted phenols, including 4-isopropyl-, and 4-propylphenol easily underwent hydrogenation and deoxygenation (Table 1, entries 1 and 9-11), whereas 4-propylguaiacol and 4-(2-propenyl)-guaiacol gave slightly lower HDO degree due to presence of three oxygenated substituents (Table 1, entries 12 and 13). Noteworthy is also that 4-propensyringol was transformed not only to 4-propylcyclohexane, but also to 4-propylcyclopentane indicating that in addition to deoxygenation and ring hydrogenation in this case ring contraction occurred (Table 1, entry 14).

For eugenol HDO under 30 bar at $250{ }^{\circ} \mathrm{C}$ the main product was, however, dihydroeugenol showing difficulties to hydrogenate the phenyl ring at these conditions (Table 1, entry 15) [49], whereas at elevated temperature and pressure the main product was 4-propylcyclohexane [62]. The same was valid for HDO of vanillin which maximally gave $65 \%$ selectivity towards methylcyclohexane at $300{ }^{\circ} \mathrm{C}$ under 50 bar over $\mathrm{Ni} / \mathrm{SiO}_{2}-\mathrm{ZrO}_{2}$ catalyst (Table 1, entry 16). The main product from vanillyl alcohol HDO is 1,4-dimethoxyphenol using $\mathrm{ZnCl}_{2}$ as a catalyst in methanol (Table 1, entry 17) [21]. Transanthole contains both propyl and methoxy substituents and it is easy to deoxygenate (Table 1, entry 18). Phenylacetate formed in bio-oil via a reaction between acetic acid and phenol underwent $\mathrm{HDO}$ at $325^{\circ} \mathrm{C}$ under 5 bar hydrogen over $\mathrm{Pt} / \mathrm{Al}_{2} \mathrm{O}_{3}$ catalyst [61]. At elevated temperature due to thermodynamic limitations the main product was phenol (Figure 4, Table 1, entry 19) [61]. 
Table 4. Comparison of the HDO using mixtures or bio-oil. Notation: $\mathrm{X}$ is conversion, $\mathrm{Y}$ yield and S selectivity.

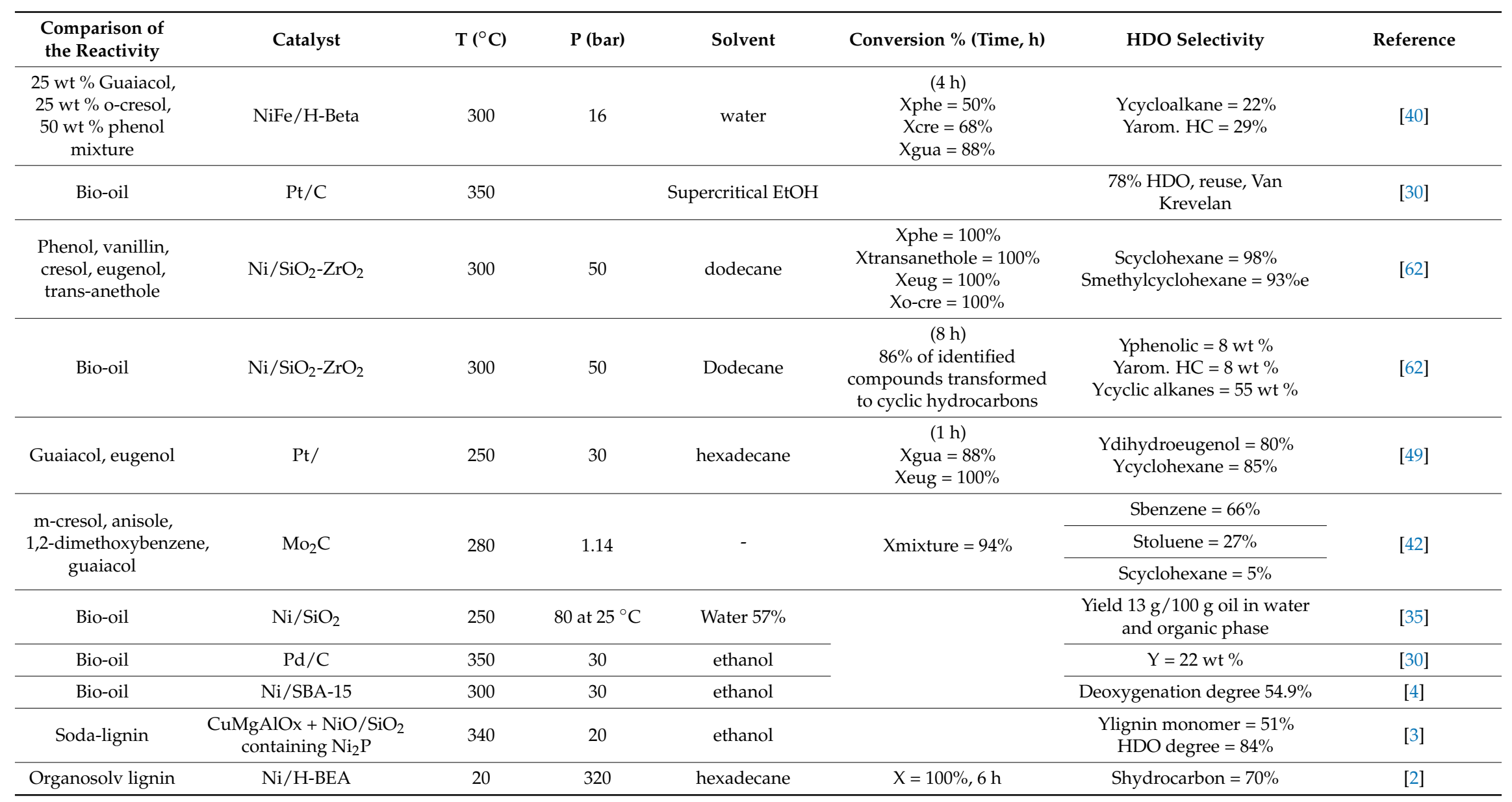




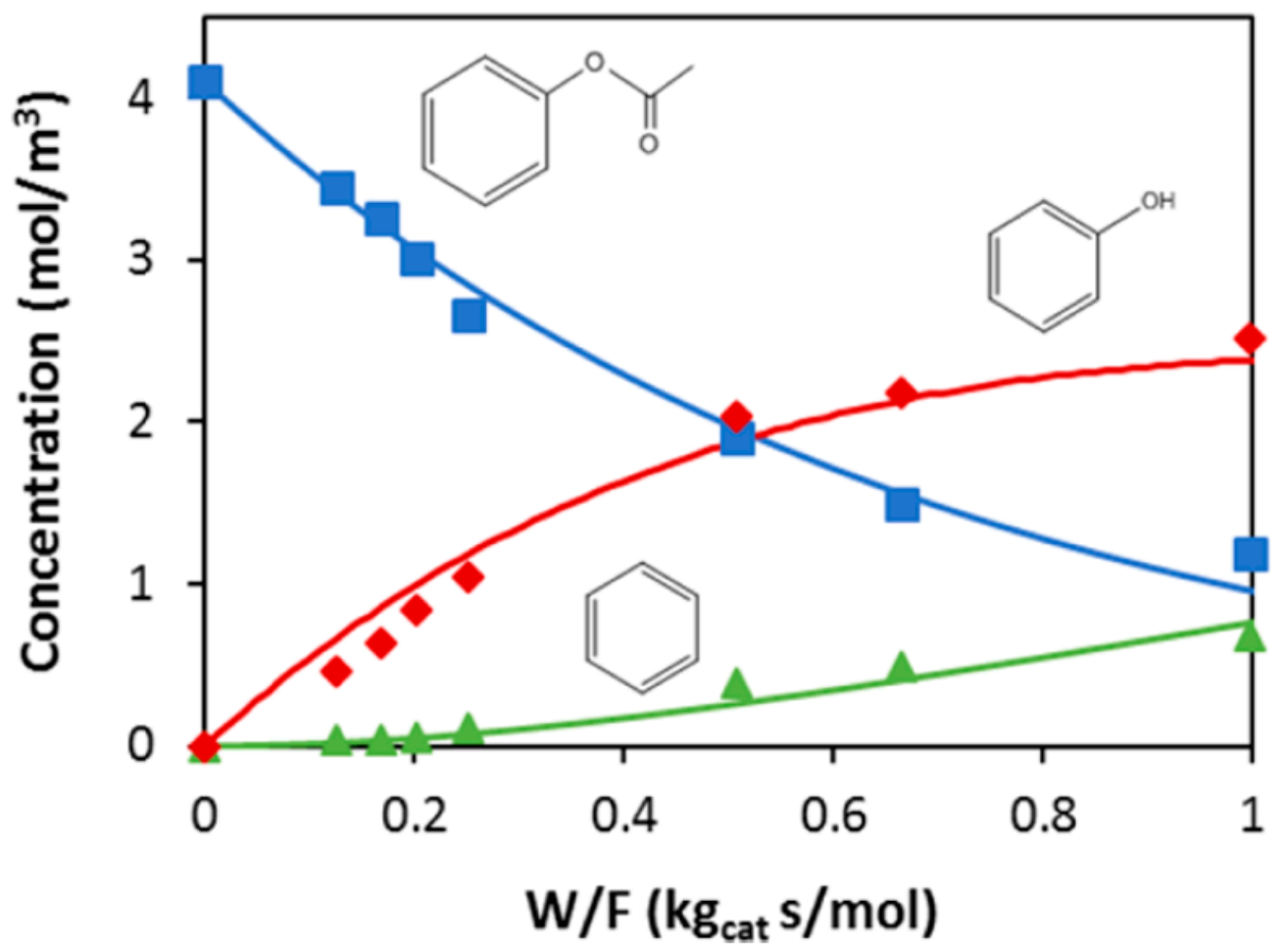

Figure 4. Results from kinetic results of the gas-phase $\mathrm{HDO}$ of phenyl acetate over $\mathrm{Pt} / \mathrm{Al}_{2} \mathrm{O}_{3}$ catalyst at $325{ }^{\circ} \mathrm{C}$ under 5 bar with $\mathrm{H}_{2} / \mathrm{O}$ ratio of 23 [61].

Dimeric compounds, such as biphenyl ether and the corresponding 4,4-dihydroxydiphenyl ether can be also easily deoxygenated to cycloalkanes (Table 1, entries 20 and 21), whereas a synthetic $\beta$-O-4 lignin dimer, guaiacylglycerol- $\beta$-4-O-guaiacyl could only be transformed to 2-methoxyphenol and guaiacol via breaking the ether linkage in its $\mathrm{HDO}$ reaction performed with $\mathrm{Zn} / \mathrm{Pd} / \mathrm{C}$ system under 21 bar hydrogen at $150{ }^{\circ} \mathrm{C}$ in methanol [21]. The minor product was 3-(3-methoxy4-hydroxyphenyl)-1-propanol. Synergy between $\mathrm{Pd}$ and $\mathrm{Zn}$ promoted the bond cleavage and a further reaction of the monomeric units on the catalyst surface with spillover hydrogen.

\subsection{Comparative Studies of a Single Feed Reactant over the Same Catalysts}

From HDO of different model compounds, comprising guaiacol, anisole, phenol and o-cresol with a single reactant over the same catalyst it is possible to compare their relative reactivity, which is of high interest for industrial applications (Table 2) $[36,37,39,48]$. Results over ReOx/CNF catalyst at elevated temperature, $300{ }^{\circ} \mathrm{C}$ and pressure of 50 bar showed that conversion of four different model molecules decreased in the following order: guaiacol $=$ anisole $>$ phenol $>$ cresol (Figure 5) [37]. In the work of Prasomsri et al. [36] the corresponding reactivity was the following: diphenyl $>$ anisole $>$ guaiacol $>$ phenol $>$ o-cresol [36]. Thus, dehydroxylation of the phenyl ring is difficult $[37,39,48,61]$. Reactivity of anisole higher than guaiacol reported in [39] similarly to the work of Prasomsri et al. [36], can be explained by a higher bond dissociation energy required for the aromatic hydroxyl compared to methoxyl (Table 3). For o-cresol the preferred route is demethoxylation followed by ring hydrogenation [37]. Only when $\mathrm{HDO}$ was performed at $400{ }^{\circ} \mathrm{C}$ over Pt-Sn/CNF/Inconel nickel-(Inconel is chromium-based superalloy), guaiacol reactivity was higher than for anisole probably due to a very high temperature [48]. Biphenyl with an ether bond is easy to break, as experimentally and theoretically shown [36]. 


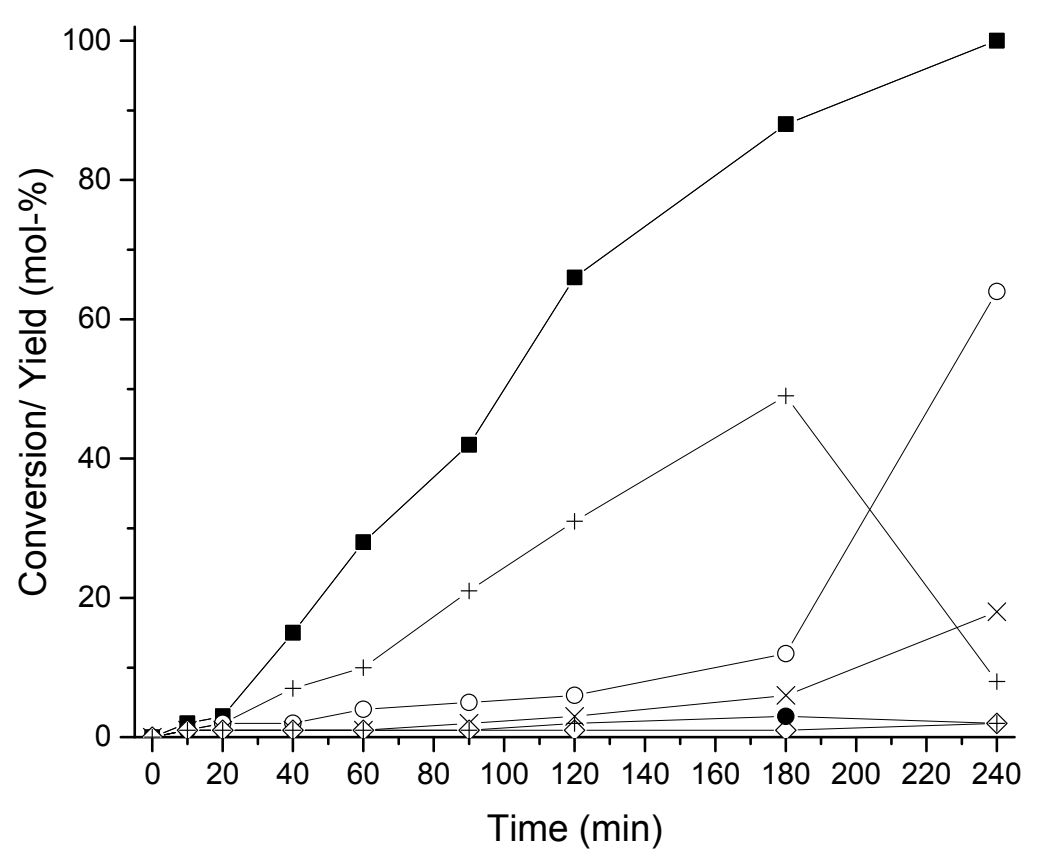

(a)

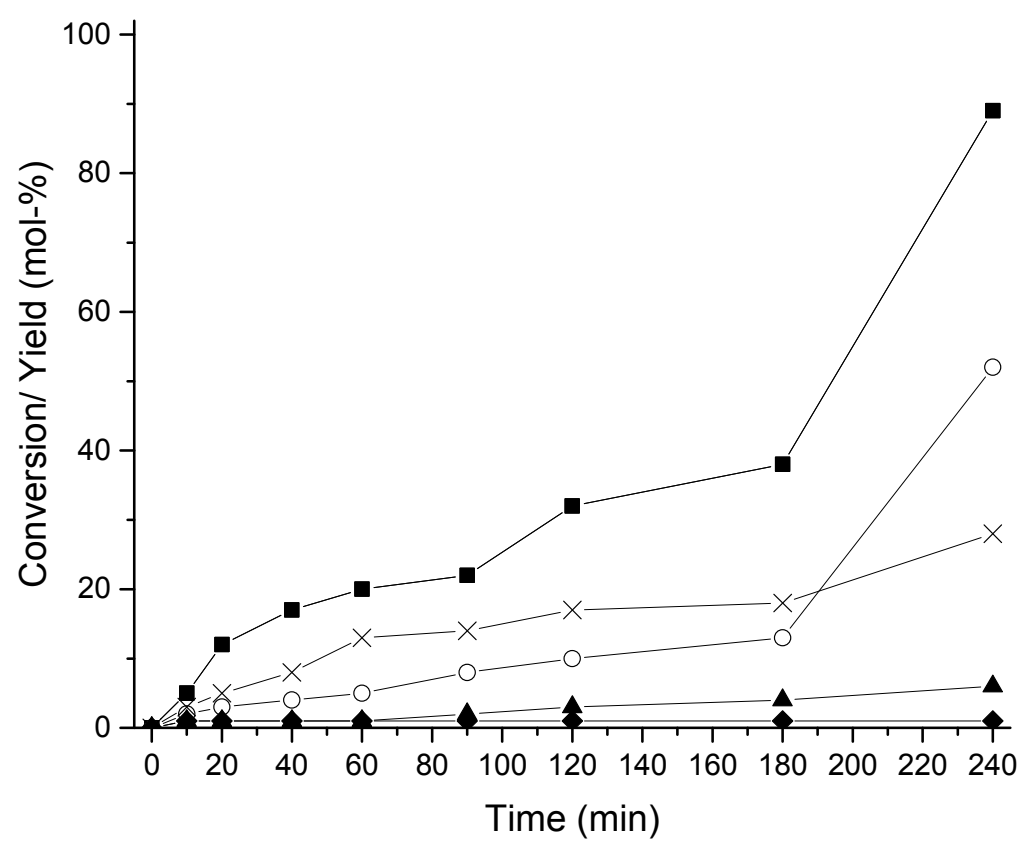

(b)

Figure 5. Cont. 


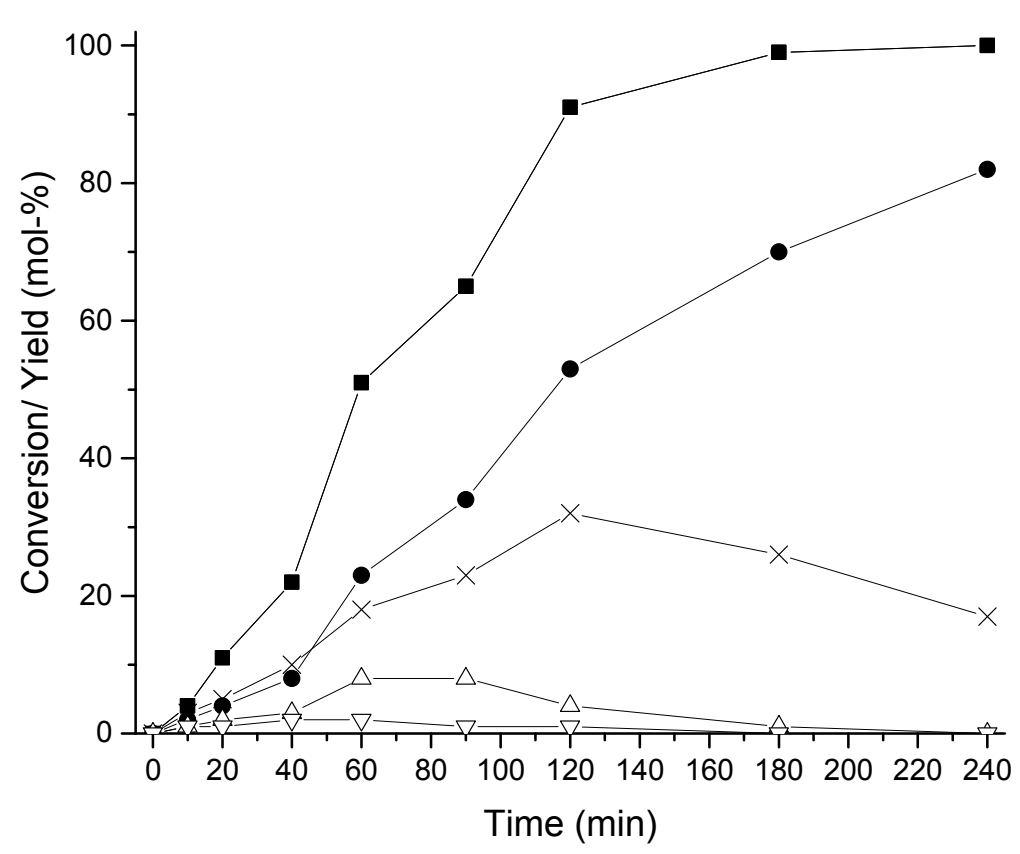

(c)

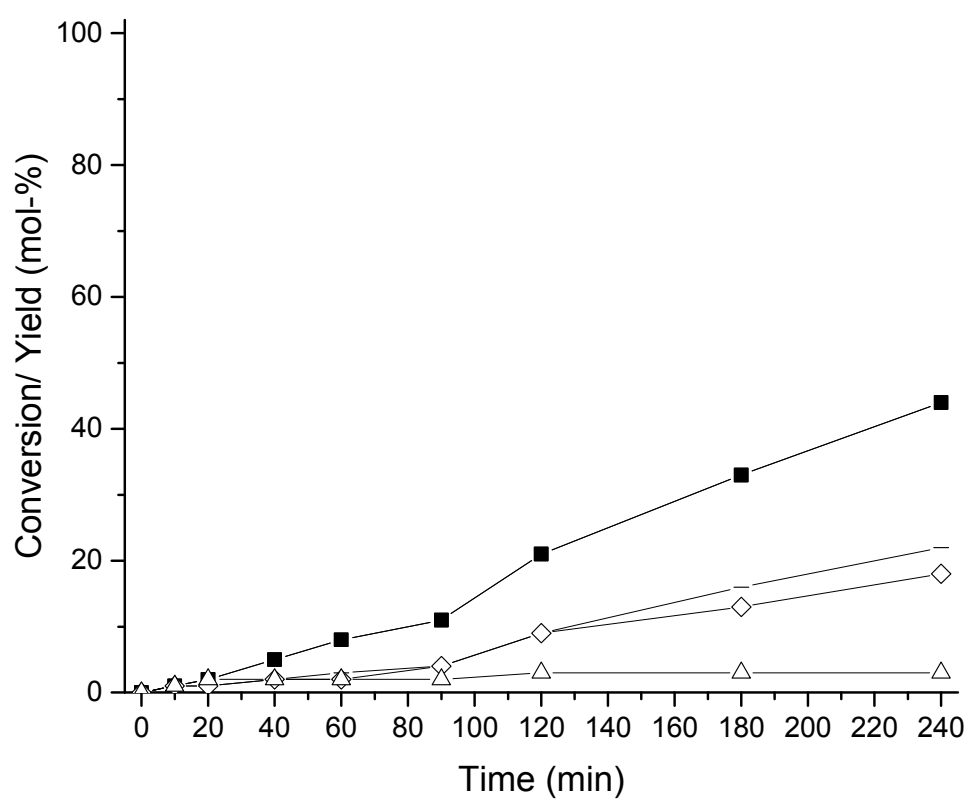

(d)

Figure 5. Comparative HDO of different model compounds over $10 \mathrm{wt} \% \mathrm{ReOx} / \mathrm{CNF}$ in dodecane at $300{ }^{\circ} \mathrm{C}$ under $5 \mathrm{MPa}$ hydrogen adapted from reference [37], HDO of (a) guaiacol; (b) phenol; (c) anisole and (d) o-cresol. Notation: $(\mathbf{\square})$ conversion, $(+)$ phenol, $(\mathrm{x})$ benzene, $(\diamond)$ toluene, $(\mathrm{o})$ cyclohexane, $(\boldsymbol{\Delta})$ methoxycyclohexane, $(\Delta)$ cyclohexanol, $(\nabla)$ cyclohexene, $(\bullet)$ lights.

In a mixture of guaiacol and eugenol a slightly higher conversion levels were obtained for $\mathrm{HDO}$ with the latter molecule at $250{ }^{\circ} \mathrm{C}$ under $30 \mathrm{MPa}$ over $\mathrm{Pt} / \mathrm{C}$ and $\mathrm{Pt} /$ aluminosilicate catalysts [49]. The main product with Pt/SA was 2-methoxy-4-propylphenol, whereas 2-methoxy-4propylcyclohexanol was mainly generated over $\mathrm{Pt} / \mathrm{C}$ [49]. It is also interesting that when dehydroxylation occurred over an acidic $\mathrm{Pt}$ supported on silica alumina, the reaction did not proceed to ring hydrogenation contrary to $\mathrm{Pt} / \mathrm{C}$. 
Temperature is one of the main parameters affecting product distribution in the HDO of phenolic mixtures. This was visible, for example, in the HDO of mixtures at high temperature, above $350{ }^{\circ} \mathrm{C}$, when aromatic compounds were the main products [39,48], whereas below this temperature non-aromatic cyclic hydrocarbons are also formed [36,37]. For example, in guaiacol $\mathrm{HDO}$, phenol was the main product in accordance with a higher bond dissociation energy for Ar-OH compared to that of $\mathrm{Ar}^{-} \mathrm{OCH}_{3}$ [39] (Table 3). In case of o-cresol HDO the main products were methylcyclohexane and toluene requiring dehydration with a high bond dissociation energy for Ar-OH probably also explaining a low conversion of o-cresol.

In the gas-phase HDO of a mixture of model compounds, m-cresol, anisole, dimethoxybenzene and guaiacol at $280^{\circ} \mathrm{C}$ under $114 \mathrm{kPa}$ over $\mathrm{Mo}_{2} \mathrm{C}$ catalyst, phenol was seen to decrease with an increase of conversion. Two other main products were benzene and toluene. These results indicated that aromatic $-\mathrm{OCH}_{3}$ bond was preferentially cleaved from guaiacol prior to the cleavage of aromatic $-\mathrm{OH}$ group [42]. These results were in accordance with the computational chemistry calculations of the bond dissociation energies being for $\mathrm{Ar}-\mathrm{OCH}_{3}$ and $\mathrm{Ar}-\mathrm{OH}$ in guaiacol equal to $376 \mathrm{~kJ} / \mathrm{mol}$ and $456 \mathrm{~kJ} / \mathrm{mol}[36]$.

\subsection{Reaction Pathways and the Thermodynamic Feasibility of Different Reactions during HDO of Model Compounds}

Since several different reactions occur during HDO of model compounds one of the main aims in using them is to elucidate the reaction pathways during HDO [32,37,48-50]. In addition to kinetic studies, also adsorption studies [48], theoretical DFT (density function theory) calculations [22,71-75] and bond dissociation energy calculations [36] have been performed.

\subsubsection{Kinetic Studies Elucidating the Reaction Pathways during HDO of Model Compounds}

Guaiacol hydrodeoxygenation can proceed via either demethoxylation pathway forming in the first step phenol at $300{ }^{\circ} \mathrm{C}$ under 50 bar hydrogen over ReOx/CNF (Figures 5 and 6) [37] and mainly phenol over Ni-catalysts at $350{ }^{\circ} \mathrm{C}$ (Figure 7) [50] or alternatively via dehydroxylation pathway forming first phenol and subsequently cyclohexanol and finally cyclohexane at moderate temperature, when hydrogenation is thermodynamically feasible, e.g., over $\mathrm{Pt} /$ silica aluminate at $250{ }^{\circ} \mathrm{C}$ under 30 bar hydrogen [49] and above $250{ }^{\circ} \mathrm{C}$ over an Rh catalyst (Figure 8) [45]. Phenol was also the main product in guaiacol HDO at $400{ }^{\circ} \mathrm{C}$ under atmospheric conditions over Co/Al-MCM-41 [34]. These results clearly show that both the metal type and reaction conditions, i.e., pressure and temperature, are decisive for the product distribution, for example, towards ring hydrogenation or HDO products. On acidic catalysts catechol is formed as the major product from guaiacol and anisole having low reactivity for further transformations [32]. Substantial amounts of catechol were also formed over Pt/C catalyst in $\mathrm{HDO}$ of guaiacol at $300{ }^{\circ} \mathrm{C}$ under atmospheric pressure (Figure 9) [22]. Further reaction is very slow due to strong adsorption on the catalyst surface, in line with DFT calculations (see Section 3.3.2) [22]. It is also interesting to note that catechol formation was more prominent in $\mathrm{HDO}$ of guaiacol over $\mathrm{Ru} / \mathrm{C}$ catalyst at $350{ }^{\circ} \mathrm{C}$ than at $400{ }^{\circ} \mathrm{C}$, which was probably also related to temperature dependence of adsorption, namely low desorption of catechol at lower temperature [16]. According to a DFT study for $\mathrm{Ru}(0001)$ surface it was concluded that catecholate is formed prior to phenolate, finally yielding phenol as the main product [74]. 


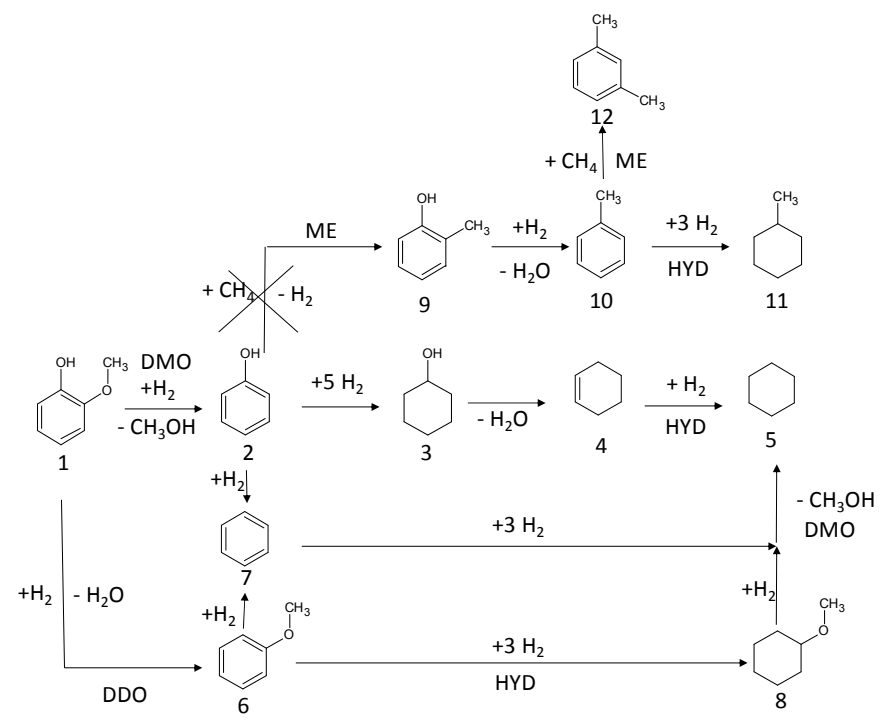

Figure 6. Reaction scheme for guaiacol $\mathrm{HDO}$ at $300^{\circ} \mathrm{C}$ under 50 bar hydrogen over ReOx/CNF catalyst adapted from reference [37]. Notation: 1. guaiacol, 2, phenol, 3. cyclohexanol, 5. cyclohexene, 5, cyclohexane, 6. methoxybenzene, 7. benzene, 8. methoxycyclohexanol, 9. O-cresol, 10. toluene, methylcyclohexne and 11. xylene. DMO denotes demethoxylation, DDO direct deoxygenation, ME methanation and HYD hydrogenation.

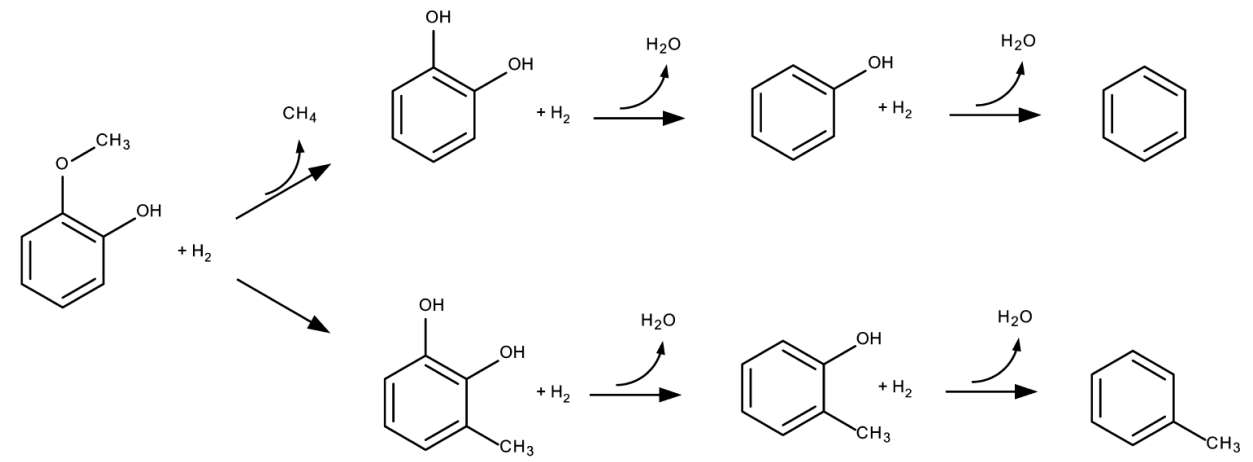

Figure 7. Proposed reaction network for guaiacol hydrodeoxygenation over Ni-based catalysts at $350{ }^{\circ} \mathrm{C}$ [50]. 


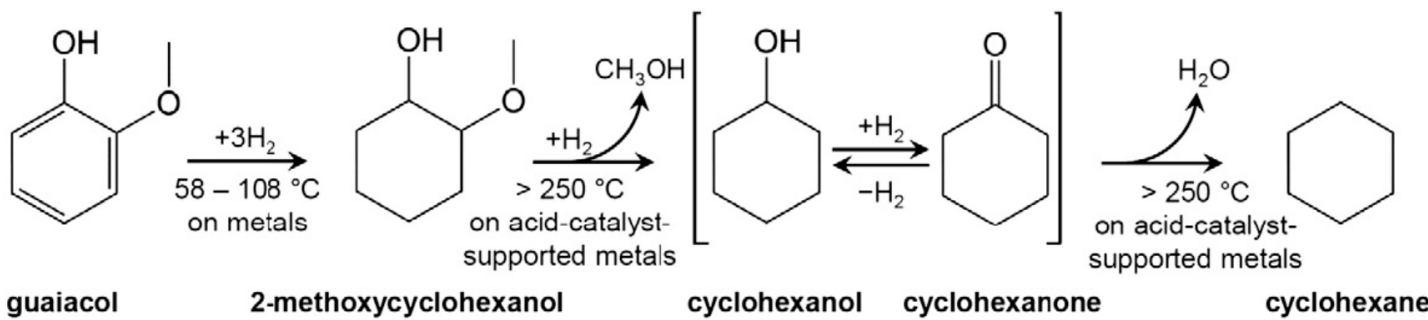

Figure 8. Guaiacol HDO over bifunctional metal supported acidic catalysts [45].

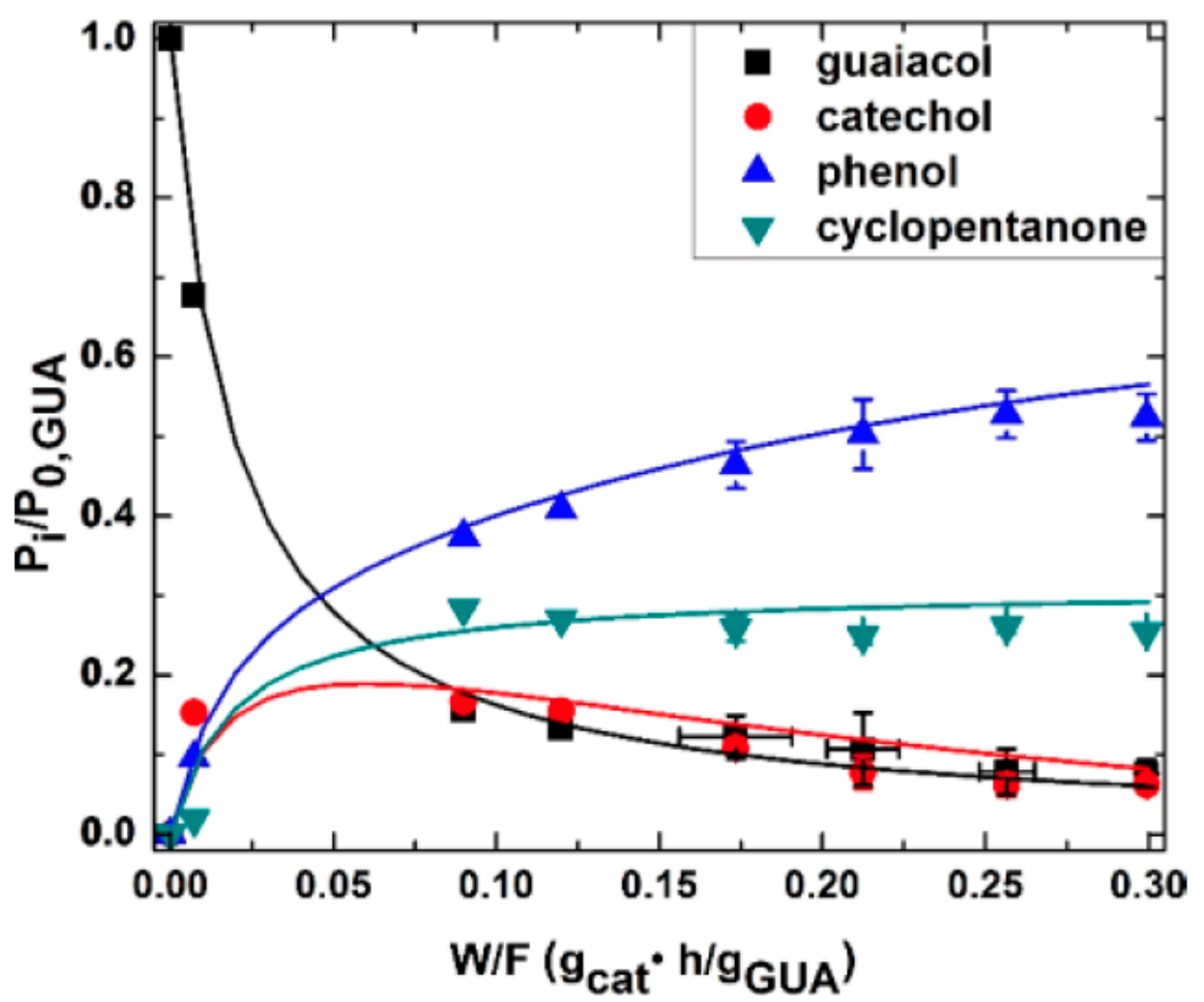

Figure 9. Kinetic for guaiacol $\mathrm{HDO}$ over $\mathrm{Pt} / \mathrm{C}$ catalyst at $300{ }^{\circ} \mathrm{C}$ under atmospheric pressure [22].

In case of anisole the reaction rate is very high due to demethoxylation occurring more easily for anisole compared to guaiacol, most probably due to a strong adsorption of the hydroxyl group lowering demethoxylation rate of guaiacol [37]. Phenol dehydroxylation is rather slow due to a high bond dissociation energy required for phenolic hydroxyl group as already mentioned. In addition, dehydroxylation rate is diminished for methyl substituted phenols due to steric hindrance.

In eugenol $\mathrm{HDO}$ the following reaction network was proposed over Pd supported on $\mathrm{Al}_{2} \mathrm{O}_{3}$, $\mathrm{SiO}_{2}, \mathrm{C}$ and alumina silicate catalysts at $250{ }^{\circ} \mathrm{C}$ under 30 bar hydrogen in hexadecane (Figure 10): hydrogenation forming 2-methoxy-4-propylcyclohexanol followed by its demethoxylation and hydrolysis forming 2-hydroxy-4-propylcyclohexanol and methanol [49]. Over acidic sites dehydration of hydroxypropylcyclohexanol can happen with further hydrogenation to the corresponding saturated compound. In addition, dealkylation can occur on the acidic sites causing cleavage of the propyl chain, finally forming cyclohexanol. These results show also difficulties of deoxygenation over $\mathrm{Pd} / \mathrm{C}$. In addition, $\mathrm{HDO}$ of 2-methyl-4-propylphenol was tested using a mixture of Pd/C-H-ZSM-5 giving a relatively high conversion and yield for mainly propylcyclohexene [27] showing that some acidity is needed for HDO. In eugenol HDO the best selectivity towards the desired product was achieved using $\mathrm{Pd} / \mathrm{C}$ and H-ZSM-5 (Figure 11). HDO activity increased with acidity increase. The kinetic diameter 
of eugenol is, however, smaller than the pore size of H-ZSM-5. Alkali leached H-ZSM-5 exhibiting mesopores was used in eugenol HDO giving $60 \%$ selectivity to hydrocarbons at $240{ }^{\circ} \mathrm{C}$ under 50 bar hydrogen [27]. It was stated by Zhang et al. [27] that the key factors inhibiting transformations of polysubstituted phenols are sterical hindrance, for example, the bulkiness of the alkyl substituent in the aromatic ring.

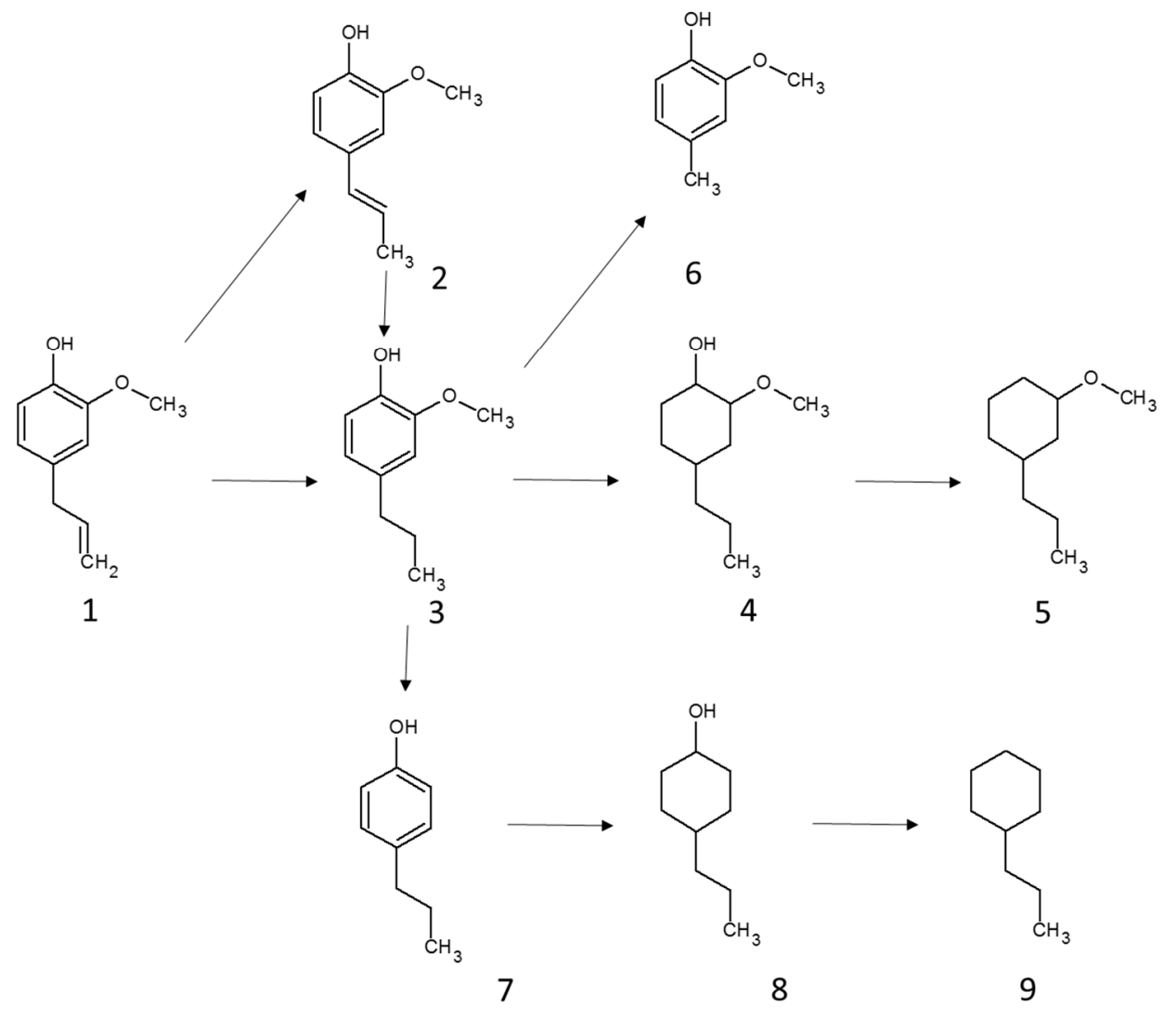

Figure 10. Reaction scheme for eugenol $\mathrm{HDO}$ over various $\mathrm{Pd}$ catalysts supported on $\mathrm{Al}_{2} \mathrm{O}_{3}$, $\mathrm{SiO}_{2}$, carbon and aluminosilicate under 30 bar hydrogen at $250{ }^{\circ} \mathrm{C}$ in hexadecane as a solvent adapted from reference [49]. Notation: 1. Eugenol, 2. Isoeugenol, 3. 2-methoxy-4-propylphenol, 4. 2-methoxy-4-propylcyclohexanol, 5. 3-propylmethoxycyclohexane, 6. 4-methyl-2-methoxyphenol, 7. 4-propylphenol, 8. 4-propylcyclohexanol and 9. propylcyclohexane.

In vanillin $\mathrm{HDO}$ full deoxygenation was not achieved at $150{ }^{\circ} \mathrm{C}$ under 10 bar hydrogen in water over mesoporous $\mathrm{Pd} / \mathrm{TiO}_{2}-\mathrm{CNx}$ giving the main product 2-methoxy-4-methylphenol with $78 \%$ selectivity at $91 \%$ conversion [29]. The reaction proceeded via hydrogenation of the aldehyde group followed by dehydroxylation of the formed alcohol (Figure 12). The pressure applied was not sufficient to hydrogenate the phenyl ring while acidity was not enough to catalyze deoxygenation.

Cleavage of lignin $\beta$-O-4-link model molecules has been experimentally investigated over $\mathrm{CuO} / \gamma-\mathrm{Al}_{2} \mathrm{O}_{3}$ catalyst at $150^{\circ} \mathrm{C}$ under 25 bar hydrogen. The experimental results have been confirmed by calculating the bond dissociation energies of the corresponding compounds [53]. 


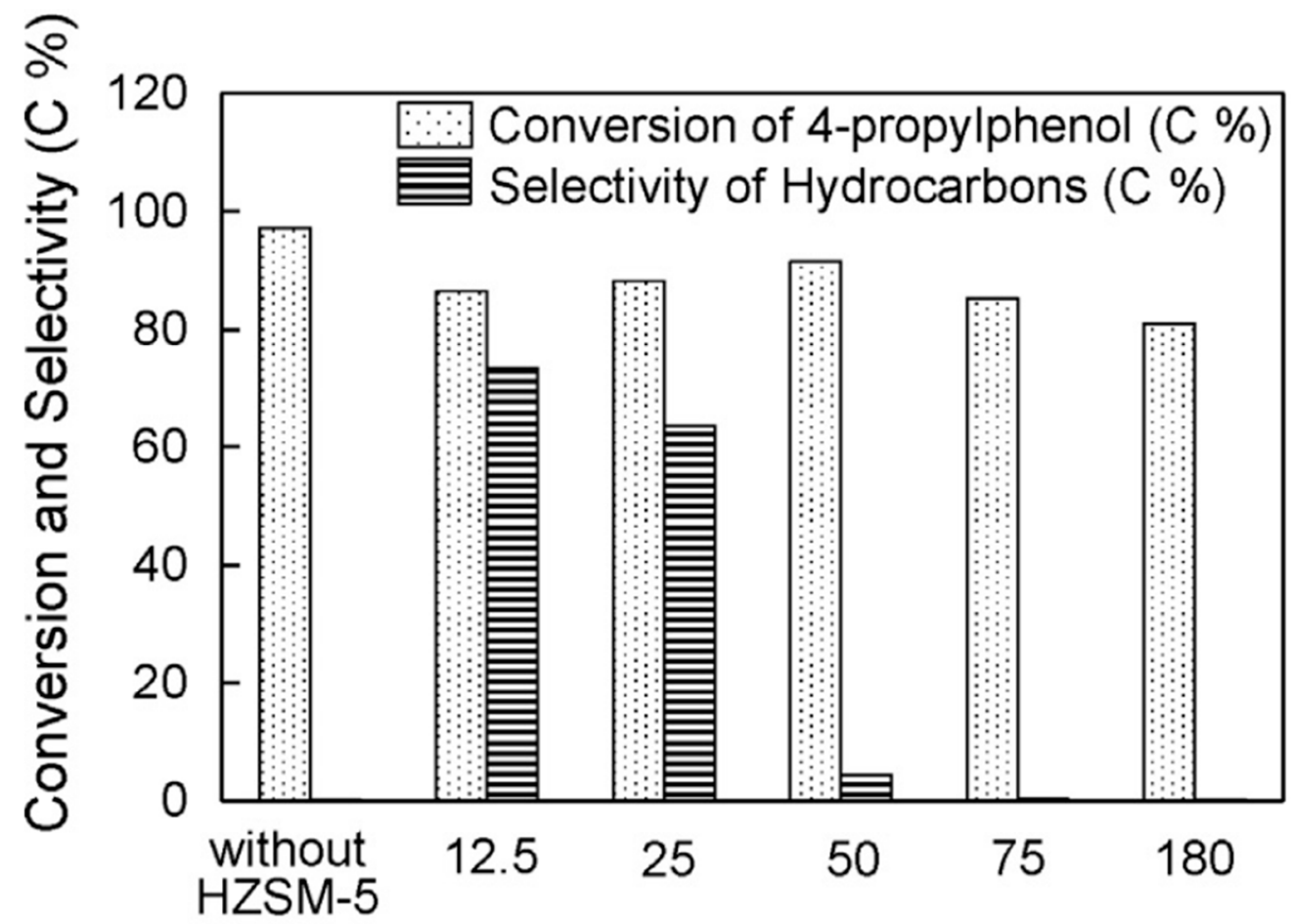

\section{$\mathrm{Si} / \mathrm{Al}$ ratio of $\mathrm{HZSM}-5$}

Figure 11. Conversion and product selectivity in $\mathrm{HDO}$ of eugenol at $240{ }^{\circ} \mathrm{C}$ under 50 bar hydrogen after 4 h over Pd/C catalyst together with HZSM-5 with different acidity [27].

(a)<smiles>COc1cc(C=O)ccc1O</smiles>

(b)<smiles>COc1cc(C)ccc1O</smiles>

Figure 12. Reaction scheme for HDO of vanillin under 10 bar hydrogen in water at $70-150{ }^{\circ} \mathrm{C}$ over $\mathrm{Pd} / \mathrm{TiO}_{2}$ adapted from reference [29]. Notation (a) vanillin; (b) 4-hydroxymethyl-2-methoxyphenol and (c) 2-methoxy-4-methylphenol.

\subsubsection{Different Reactions and Their Thermodynamic Feasibility in HDO of Model Compounds}

Thermodynamic feasibility of different reactions occurring during HDO of lignin based model molecules together with the specific catalyst properties are summarized below. During HDO several reactions, such as demethoxylation, hydrogenation, transalkylation, hydrogenolysis, demethylation, ring opening, decarbonylation, oligomerisation can occur.

Demethoxylation is one of the main desired reactions for HDO occurring typically at relatively high temperature prior to dehydroxylation during guaiacol HDO [50]. Demethoxylation of 1,3,5-trimethoxybenzene followed by ring hydrogenation occurred over Rh/MCM-36 at $250{ }^{\circ} \mathrm{C}$ under 40 bar hydrogen in decane [26]. It was concluded in [34] that demethoxylation was catalyzed by metal sites using Co- and Ni-catalysts supported with Al-MCM-41 at $400{ }^{\circ} \mathrm{C}$ under atmospheric pressure [34]. Cyclopentanone formation occurred during $\mathrm{HDO}$ of guaiacol over $\mathrm{Pt} / \mathrm{C}$ catalyst at $300{ }^{\circ} \mathrm{C}$ under 
atmospheric pressure [31]. The proposed reaction network for guaiacol $\mathrm{HDO}$ proposed over $\mathrm{Pt} / \mathrm{C}$ is shown in Figure 13a. Cyclopentanone was formed via hydroxycycloalkene intermediate and its ring opening [41]. Slow demethoxylation of guaiacol observed experimentally was in agreement with DFT calculations for HDO on $\mathrm{Pt}(111)$ surface (Figure 13b) [22] leading to formation of large amounts of catechol. Formation of cyclopentanone was confirmed by DFT calculations made for guaiacol HDO over $\mathrm{Pt}(111)$. This product can be formed by partial hydrogenation of the aromatic ring in guaiacol followed by formation of alpha diketone which undergoes decarbonylation and ring closing [22]. Analogous results were reported by Lee et al. [68] who performed DFT calculations for Pt(111) surface.
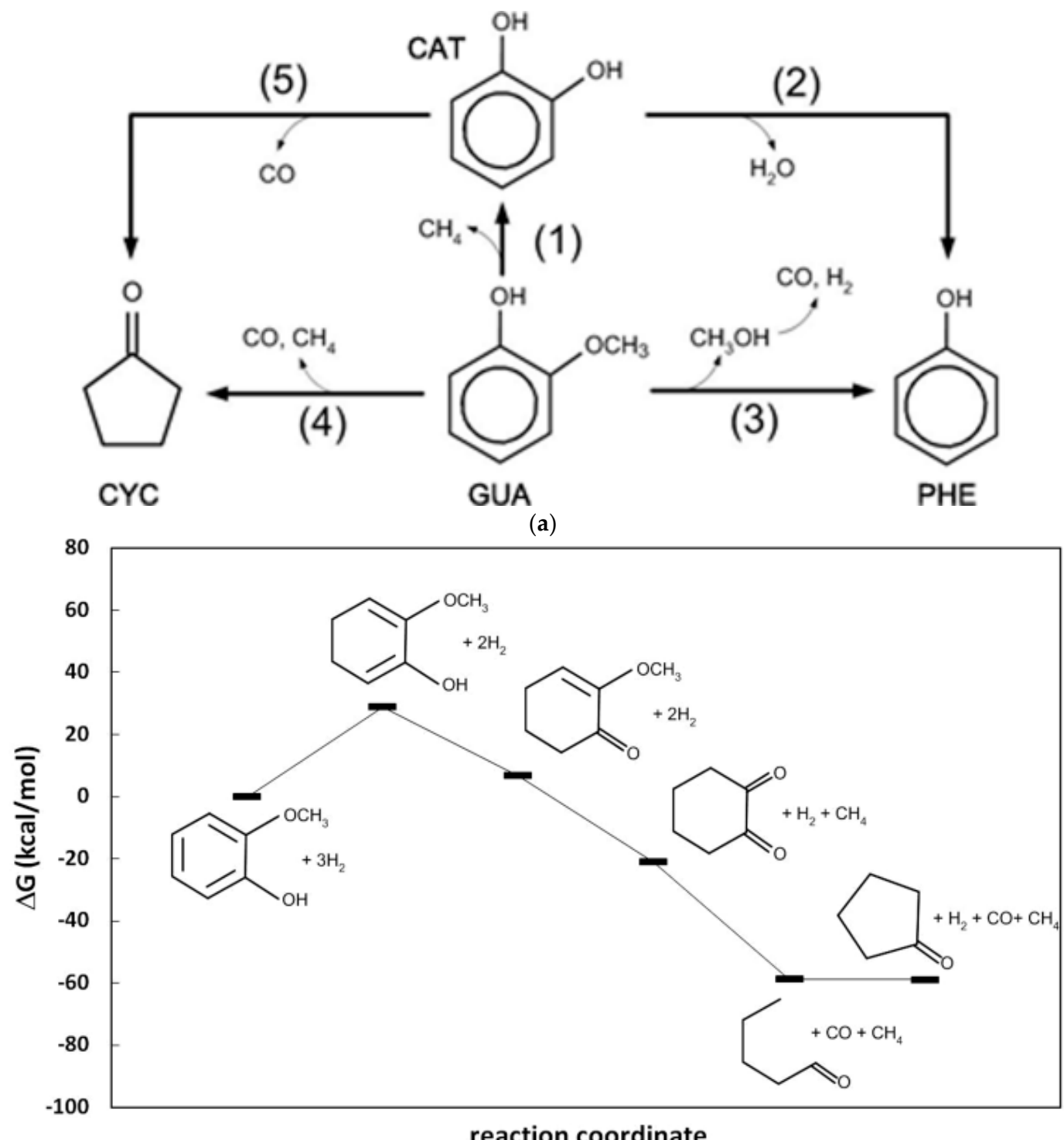

(b)

Figure 13. (a) Reaction scheme for $\mathrm{HDO}$ of guaiacol over $\mathrm{Pt} / \mathrm{C}$ catalyst in the temperature range of $275-325^{\circ} \mathrm{C}$ under atmospheric pressure over $\mathrm{Pt} / \mathrm{C}$ and (b) energy levels for reaction coordinate calculated with DFT for Pt(111) surface [22].

Demethoxylation of dihydroeugenol resulting in formation of 4-propylphenol requires acidity (Figure 10) [49]. In temperature programmed $\mathrm{HDO}$ of guaiacol at $280{ }^{\circ} \mathrm{C}$ over $\mathrm{Rh} / \mathrm{ZrO}_{2}$ together with aluminosilicate under 40 bar hydrogen in decane complete demethoxylation of guaiacol was achieved at $280{ }^{\circ} \mathrm{C}$ showing clearly its easiness for breaking this bond (Figure 14) (Table 3) [45]. It was also stated in [37] that ReOx/CNF is a promising catalyst favoring C-O bond cleavage and forming 
phenol at $300{ }^{\circ} \mathrm{C}$ under 50 bar hydrogen (Figures 5 and 6) without breaking $\mathrm{C}-\mathrm{C}$ bond being thus hydrogen efficient and carbon atom economical catalyst. Demethoxylation was faster compared to transalkylation in continuous HDO of a phenylacetate and anisole mixture at $325^{\circ} \mathrm{C}$ under 5 bar hydrogen over $\mathrm{Pt} / \mathrm{C}$ catalyst [61] and thus it was proposed that anisole is converted more preferentially to phenol than to m-cresol.
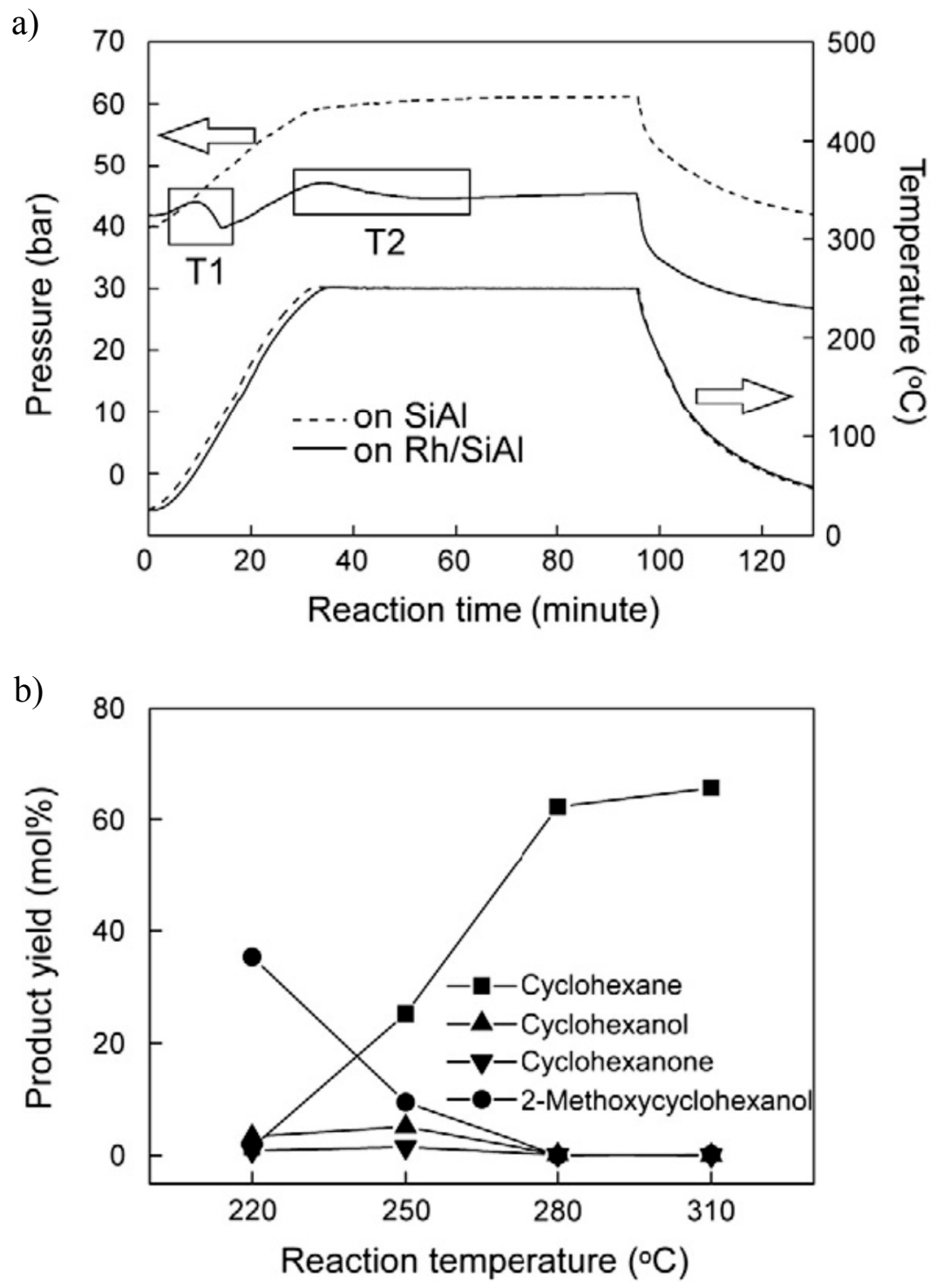

Figure 14. (a) Temperature and pressure profiles during HDO of guaiacol; (b) yields of different products in HDO of guaiacol as a function of temperature, solvent decane [45].

Dehydroxylation of the phenyl ring is thermodynamically more demanding than demethoxylation (Table 3) [22,36]. Substantial amounts of catechol were formed from guaiacol prior to phenol formation showing apparent difficulties of direct phenol formation from guaiacol at $300{ }^{\circ} \mathrm{C}$ over $\mathrm{Pt} / \mathrm{C}$ [22]. Typically demethoxylation of bulky 1,3,5-trimethoxybenzene was rather slow even over mesoporous $\mathrm{Rh} / \mathrm{MCM}-36$ at $250{ }^{\circ} \mathrm{C}$ under 40 bar hydrogen due to the sterical hindrance, despite the fact that it is easy to break the methoxy bond compared to the hydroxyl bond connected to the phenyl ring [26].

Substantial demethylation has been observed over Ni-, Fe-based catalysts [50] as well as over $\mathrm{Mo}_{2} \mathrm{~S}$ and $\mathrm{CoMoS}$ catalysts [46] in $\mathrm{HDO}$ of guaiacol at relatively high temperatures. Methanation was also observed in $\mathrm{HDO}$ of guaiacol over $\mathrm{CoMo} / \mathrm{ZrO}_{2}$ catalyst at $300{ }^{\circ} \mathrm{C}$ under 50 bar hydrogen [46] and $\mathrm{Co} / \mathrm{Al}-\mathrm{MCM}-41$ at $400{ }^{\circ} \mathrm{C}$ under 1 bar [34]. In the latter work it was concluded that demethylation 
occurs only on the acid sites especially with high catalyst weight to flow rate [34]. Methanation could however, be inhibited in guaiacol HDO via transalkylation increasing the carbon efficiency [34,50]. On the other hand, a very low methanation activity occurred in $\mathrm{HDO}$ of anisole at $320^{\circ} \mathrm{C}$ under 1 bar using $\mathrm{MoO}_{3} / \mathrm{ZrO}_{2}$ catalyst [51]. It is also noteworthy that substantial methanation occurred in HDO of guaiacol and anisole over Pt-Sn/CNF [48]. In addition, methanation is especially promoted by Rh and $\mathrm{Ru}[76]$.

Methanation in anisole $\mathrm{HDO}$ increased with increasing temperature over $\mathrm{Mo}_{2} \mathrm{C}$ [43]. Phenol and methanol were the primary products in anisole $\mathrm{HDO}$ over $\mathrm{Mo}_{2} \mathrm{C}$, whereas methanol deoxygenated to methane at higher temperatures [43]. It was thus concluded that $\mathrm{Mo}_{2} \mathrm{C}$ is capable for breaking phenolic $\mathrm{C}-\mathrm{O}$ bond in anisole at low temperature. Demethylation of guaiacol involves $\mathrm{C}(\mathrm{sp} 3)-\mathrm{O}_{\mathrm{ar}}$ and is from the thermodynamic point of view the easiest reaction compared to, e.g., phenol, via C(sp2)-OMe cleavage [46]. Non-promoted $\mathrm{MoS}_{2}$ catalyst was beneficial for demethylation [46]. 2-methylphenol is formed over $\mathrm{CoMoS} / \mathrm{Al}_{2} \mathrm{O}_{3}$ via adsorption of the methoxy oxygen group followed by methylation of the phenyl ring. The deoxygenation of methoxyphenol is more difficult than that of phenol [77].

Ring hydrogenation is thermodynamically favored during HDO of phenolic compounds under high pressure using relatively low temperatures $[27,37,45,47-49,62,63]$. Such ring hydrogenation makes the overall process more expensive because of hydrogen consumption. Typically hydrogenation during HDO is favored over supported Ni catalysts [47,62], CoNx [63], $\mathrm{Rh} / \mathrm{ZrO}_{2}$ with the mixture of aluminosilicates [43], $\mathrm{Pt}$ /alumina [49] and even with $\mathrm{MoO}_{3}$ [36]. If the target is to perform HDO to produce BTX products, lower hydrogen consumption can be achieved under high temperatures [16,34]. For example, no ring hydrogenation occurred in $\mathrm{HDO}$ of guaiacol and anisole at $400{ }^{\circ} \mathrm{C}$ and $1 \mathrm{bar}$ over Pt-Sn/CNF [48]. At the same temperature nickel and iron catalysts were also inefficient for hydrogenation $[33,50]$. Even when using 60 bar at $350{ }^{\circ} \mathrm{C}$ in anisole and phenol HDO, the main product was benzene over $\mathrm{MoO}_{3} / \mathrm{ZrO}_{2}$ catalyst showing clearly thermodynamic limitations at this temperature [39].

Ring hydrogenation in HDO of 4-propylphenol occurred with very high selectivity over $\mathrm{Pt} / \mathrm{AC}$ at $280{ }^{\circ} \mathrm{C}$ under 40 bar hydrogen giving propylcyclohexane as the main product [57]. It was also pointed out that under these conditions using water as a solvent, protons can be formed increasing acidity of the reaction media [57]. Slightly lower yields of propylcyclohexane were achieved in HDO of 4-propylguaiacol, since $\mathrm{Pt} / \mathrm{AC}$ catalyst promoted also formation of propylcyclopentane [57].

In eugenol HDO, ring hydrogenation occurred after demethoxylation over supported Pd catalysts under 30 bar hydrogen at $250{ }^{\circ} \mathrm{C}$ in hexadecane as a solvent [49]. It should, however, be noticed that ring hydrogenation could occur already prior to dehydroxylation [49]. Noteworthy is that 10 bar hydrogen was not sufficient to facilitate ring hydrogenation during vanillin $\mathrm{HDO}$ over Pd/CNF catalyst in the temperature range of $70-150^{\circ} \mathrm{C}$ in water [29]. Acidic catalysts are active in HDO facilitating often complete conversion of phenolic compounds, but not hydrogenation $[25,55]$, for example, vanillin transformation to p-creosol [25].

Transalkylation occurring after demethylation is beneficial for carbon efficiency [50] and it is favored by acidic catalysts [32]. Several transalkylated C7-C12 products were formed in guaiacol HDO at $400{ }^{\circ} \mathrm{C}$ under atmospheric pressure due to acidity of Co-Ni-Al-MCM-41 [34]. $\mathrm{MoO}_{3} / \mathrm{ZrO}_{2}$ promoted also transalkylation in anisole $\mathrm{HDO}$ at $350{ }^{\circ} \mathrm{C}$ under 60 bar hydrogen [39]. It was also proposed based on the product distribution that transalkylation occurred parallel with hydrogenolysis [39]. On the other hand, no transalkylation occurred with $\mathrm{Mo}_{2} \mathrm{C}$ in $\mathrm{HDO}$ of a mixture of anisole, m-cresol, dimethoxybenzene and guaiacol at $280{ }^{\circ} \mathrm{C}$ under $114 \mathrm{kPa}$ [42]. These results suggest that temperature is one of the decisive factors determining the transalkylation activity. A low alkylation ability was, however, observed in $\mathrm{HDO}$ of guaiacol at $400{ }^{\circ} \mathrm{C}$ over Pt-Sn/CNF catalyst exhibiting low acidity (Figure 15) [48]. 
<smiles>COc1ccccc1</smiles><smiles>Oc1ccccc1</smiles><smiles>COc1ccccc1</smiles><smiles>COc1ccccc1C</smiles><smiles>Cc1ccccc1O</smiles>

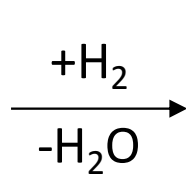<smiles>Cc1ccccc1</smiles>

Figure 15. Reaction scheme for $\mathrm{HDO}$ and transalkylation of anisole at $400{ }^{\circ} \mathrm{C}$ under 1 bar over Pt-Sn/CNF adapted from ref. [48].

Oligomerisation [25] and formation of gaseous products are also typical as evidenced from several HDO studies regarding lignin derived phenolics. As a result mass balance is very often below $100 \%$. For example, in vanillin $\mathrm{HDO}$, performed over $\mathrm{Mo}_{2} \mathrm{C} / \mathrm{AC}$ catalyst under 20 bar hydrogen at $100^{\circ} \mathrm{C}$ oligomerisation of vanillin occurred causing incomplete mass balance [25]. Analogously in guaiacol $\mathrm{HDO}$ the mass balance was not complete when performing $\mathrm{HDO}$ over $\mathrm{Mo}_{2} \mathrm{C} / \mathrm{CNF}$ in the temperature range of $300-375{ }^{\circ} \mathrm{C}$ under 55 bar hydrogen. The highest mass balance closure of ca. $96 \%$ was obtained at $375{ }^{\circ} \mathrm{C}$ [54]. It was stated [35] that in order to avoid polymerisation, stirring of the bio-oil should be started during its heating. In bio-oil $\mathrm{HDO} \mathrm{CO}_{2}$ was the main product due to the presence of carboxylic acids in the feed [35]. When comparing gaseous composition after bio-oil HDO it could be seen that $\mathrm{Ru} / \mathrm{C}$ produced more methane from $\mathrm{CO}_{2}$ than supported Ni-catalysts, in line with $80 \%$ more hydrogen consumption [35].

\subsection{HDO of Simulated and Real Bio-Oils and Lignin}

\subsubsection{HDO of Simulated Bio-Oils}

Mixtures of different phenolic compounds to simulate bio-oil have been used in HDO (Figure 16, Table 4) [40,62]. The main products in the HDO of simulated bio-oil containing phenol, o-cresol and guaiacol over Ni- and Ni-Fe/H-Beta catalysts at $300{ }^{\circ} \mathrm{C}$ during $4 \mathrm{~h}$ under 16 bar hydrogen were oxygenated aromatic compounds [40]. The lowest amount of oxygenates was produced over $\mathrm{NiFe}-\mathrm{H}$-Beta catalysts along with substantial amounts of cycloalkanes. It was also stated that water as a solvent is beneficial for HDO, whereas methanol diminished selectivity towards hydrocarbons [40]. The proposed reaction network for HDO of this simulated bio-oil is shown in Figure 17. It contains in addition to hydrogenation and deoxygenation also ring contraction of 1,2-cyclohexanediol to cyclopentanol over acidic Ni-Fe/H-Beta catalyst. In $\mathrm{HDO}$ of a mixture of phenol, cresol, eugenol and trans-anethole over $\mathrm{Ni} / \mathrm{SiO}_{2}-\mathrm{ZrO}_{2}$ at $300{ }^{\circ} \mathrm{C}$ under 50 bar during $8 \mathrm{~h}$ it was observed that this catalyst was rather efficient towards hydrocarbons with $62 \%$ selectivity to cyclohexane at $91 \%$ conversion [62]. Gas-phase pyrolytic products contain also hydrogen, $\mathrm{CO}_{2}, \mathrm{CO}$ and water vapours. Guaiacol HDO was investigated using a co-feed of the simulated pyrolysis vapors [33]. The effect of gaseous co-feed is discussed, however, in Section 3.5.6. 


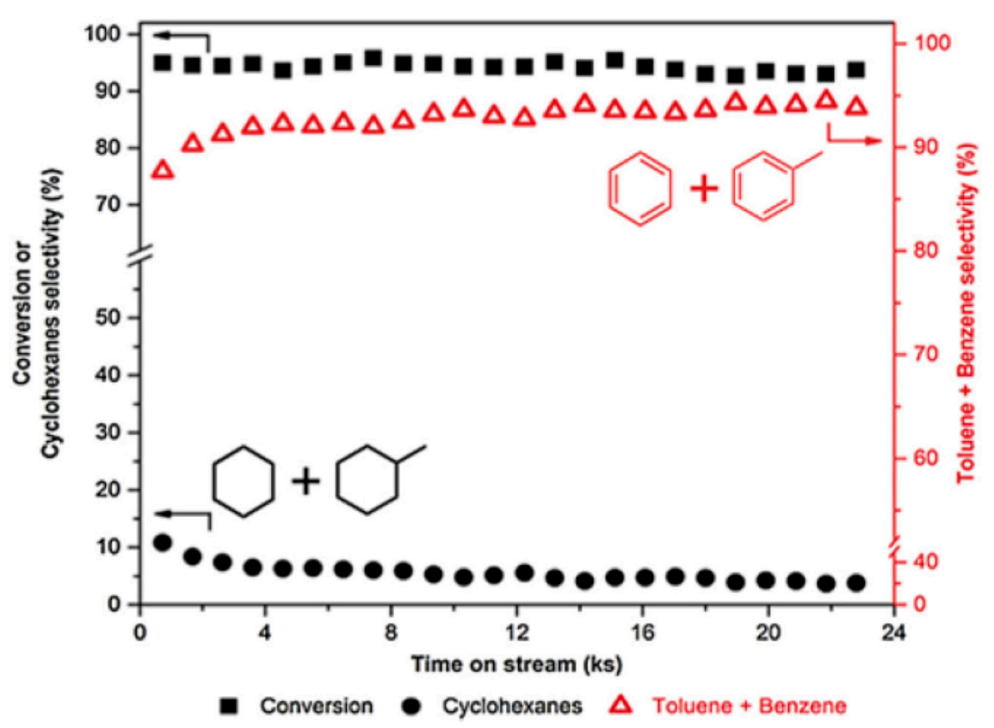

Figure 16. Conversion and selectivity to different products as a function of time on stream in HDO of a mixture of m-cresol, anisole, dimethoxybenzene and guaiacol at $280{ }^{\circ} \mathrm{C}$ under $144 \mathrm{kPa}$ over $\mathrm{Mo}_{2} \mathrm{C}$ catalyst [42].

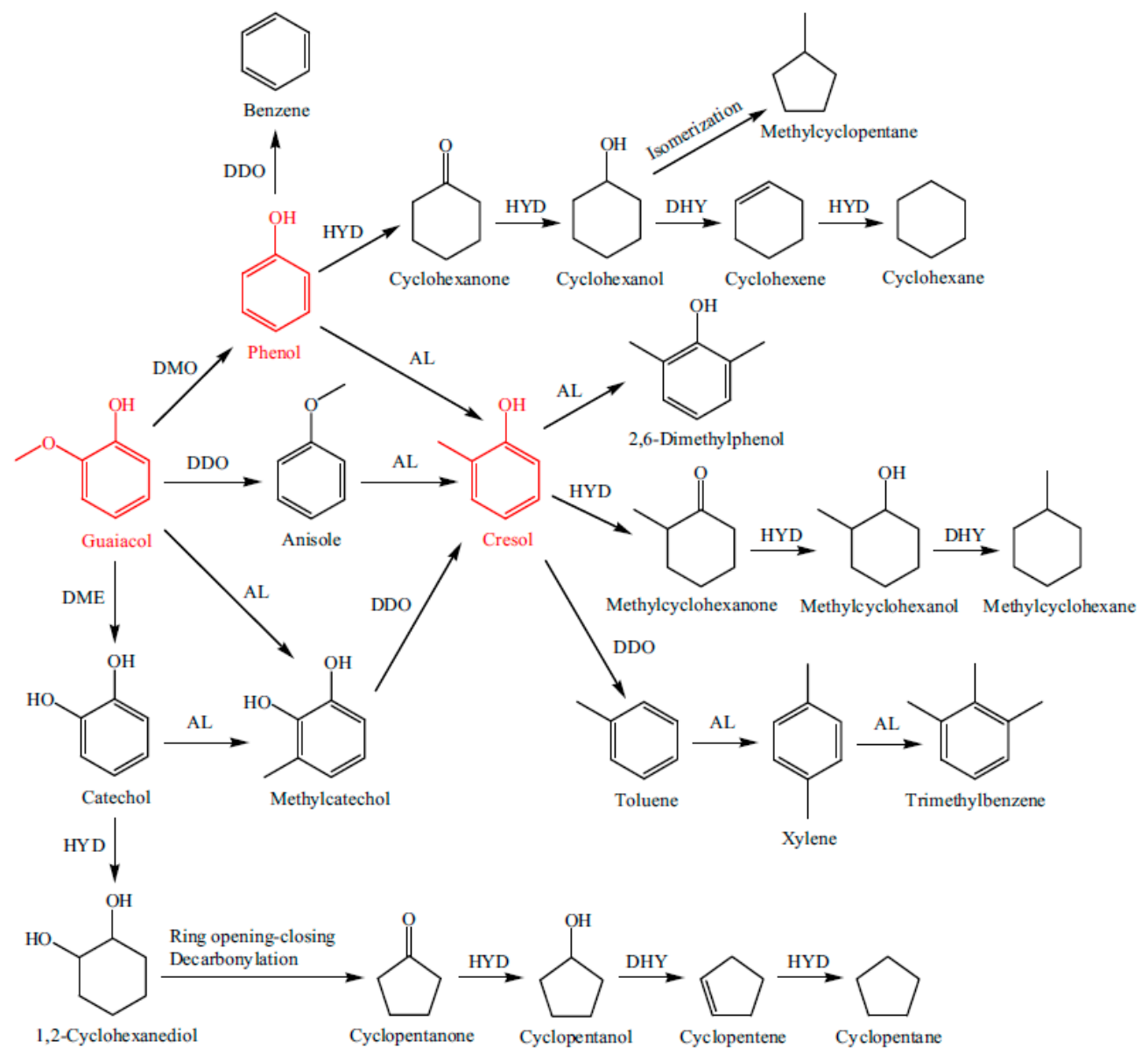

Figure 17. Proposed reaction scheme for the HDO of simulated bio-oil containing guaiacol, phenol and o-cresol as feedstock over Ni-H-Beta catalyst. Notations: DDO: direct deoxygenation, HYD: hydrogenation, DMO: demethoxylation, DME: demethylation, AL: alkylation and DHY: dehydration [40]. 


\subsubsection{HDO of Real Bio-Oil}

HDO of real bio-oils $[4,30,35,62]$ have been investigated in several publications. Bio-oil derived from yellow poplar via fast pyrolysis was hydrodeoxygenatied at $300{ }^{\circ} \mathrm{C}$ in ethanol at 30 bar hydrogen [4]. The lowest $\mathrm{O} / \mathrm{C}$ content was obtained with $\mathrm{Pt} / \mathrm{C}$ catalyst [4]. HDO of the bio-oil prepared via fast pyrolysis of Miscanthus sinensis at $350{ }^{\circ} \mathrm{C}$ and 30 bar over noble metals supported on carbon, in supercritical ethanol [30] showed deoxygenation of the heavy oil fraction of the bio-oil to $78 \%$ with the heating value of the product $27.8 \mathrm{MJ} / \mathrm{kg}$. It is also important to note that such unstable compounds, as acids, furfural, vanillin and levoglucosan were converted to esters, ketones and saturated phenols [30]. Macromolecular products in that work were also characterized [28]. The results showed that the carbon content in the polymer increased and at the same time oxygen content decreased indicating lower amounts of phenolic and hydroxyl and methoxy groups. It was also observed that after prolonged reaction times the amount of methoxy groups decreased while phenol groups remained constant indicating that dehydroxylation of the phenol groups was not feasible under these reaction conditions [28]. On the other hand, when the bio-oil was hydrodeoxygenated over $\mathrm{Pd} / \mathrm{C}$ catalyst at different temperatures varying from $250{ }^{\circ} \mathrm{C}$ to $350{ }^{\circ} \mathrm{C}$ phenolics started to polymerize [28].

In addition to $\mathrm{Pt} / \mathrm{C}$ also Ni/SBA-15 was rather active in $\mathrm{HDO}$ of bio-oil giving ca. $55 \%$

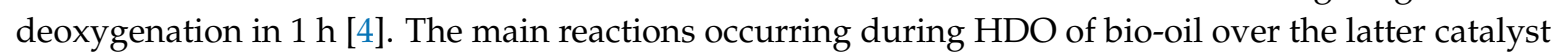
were guaiacol and 4-propylsyringol. In this case stability of the deoxygenated bio-oil was improved, since acetic acid, levoglucosan and furfural were totally converted. Gas phase products contained methane, $\mathrm{CO}$, ethane and propane. The produced heavy oil fraction contained only $9.3 \%$ water with the heating value of $22.8 \mathrm{MJ} / \mathrm{kg}$ [4].

$\mathrm{HDO}$ of a real lignin derived bio-oil was successfully carried out over $\mathrm{Ni} / \mathrm{SiO}_{2}-\mathrm{ZrO}_{2}$ catalyst at $300{ }^{\circ} \mathrm{C}$ under 50 bar hydrogen resulting in formation of $63 \%$ of cyclic hydrocarbons, out of which $8 \%$ were aromatics. In addition it was stated that most of the identified products, were cyclic hydrocarbons, such as cyclohexane, toluene and xylene exhibiting suitable vapor pressures and carbon number to be used in gasoline [62].

\subsubsection{HDO of Lignin}

Soda lignin $\mathrm{HDO}$ was investigated over various $\mathrm{Ni} / \mathrm{SiO}_{2}$ catalysts impregnated with $\mathrm{Ni}_{2} \mathrm{P}$ and also with $\mathrm{CuMgAlOx}$ [3]. The best results were obtained using a mixture of catalysts comprising $\mathrm{Ni} / \mathrm{SiO}_{2}$ containing $\mathrm{Ni}_{2} \mathrm{P}$ together with $\mathrm{CuMgAlOx}$. At $340{ }^{\circ} \mathrm{C}$ under 20 bar of hydrogen for HDO in ethanol of oxygen removal $84 \%$ was achieved with the aromatic lignin monomer yield of $51 \%$ and relatively low ring hydrogenation [3]. It was stated that the role of $\mathrm{CuMgAlOx}$ was to generate hydrogen during lignin ethanolysis [19] which in turn activates the reduced and passivated $\mathrm{Ni}_{2} \mathrm{P} / \mathrm{SiO}_{2}$ catalyst [78].

Complete conversion of organosolv lignin was obtained during its $\mathrm{HDO}$ with Ni-BEA at $320{ }^{\circ} \mathrm{C}$ under 20 bar hydrogen [2]. The hydrocarbon selectivity of $70 \%$ was reported, while the amount of water and the solid residue were $21 \%$ and $4 \%$, respectively. The reaction network includes disruption of phenolic compounds of lignin from ether linkages. Thereafter ring hydrogenation followed by deoxygenation occur over Ni-catalyst with slow hydrogenolysis. It was also concluded that at lower temperatures oligomers are formed via recombination of phenolic compounds.

\subsection{Catalyst Deactivation, Regeneration and Reuse during HDO of Phenolic Compounds}

Catalyst deactivation and continuous HDO have been intensively investigated for phenolic compounds $[31,33,42,49,50,57]$. Catalyst stability, activity as a function of time-onstream $[31,33,36,39,42,43,47,48,58,59,61]$, reuse $[30,54,56-58,63]$, regeneration [34,36], origin of the catalyst deactivation [30], chemical composition of coke [31], thermogravimetrical analysis of the spent catalysts [62], modelling of deactivation [33] are also very important from the industrial point of view. Since the real bio-oils contain in addition to lignin derived compounds also water [59], acetic acid 
or furfural [56] as well several catalyst poisons, such as chlorine, potassium and sulphur containing compounds [47], it is very important not only to investigate HDO of model compounds but also the real feed [30] using different approaches, such as a single component feed, co-feed studies, real bio-oil [30], simulated bio-oil [40], adsorption studies [48,79] as well as continuous operation [33,36,39,42,43,48].

\subsubsection{Catalyst Reuse in HDO of Model Compounds and Bio-Oils}

Reuse of the catalysts in $\mathrm{HDO}$ of phenolic compounds has been intensively investigated $[49,54,56,57,62] . \mathrm{Mo}_{2} \mathrm{C} / \mathrm{CNF}$ catalyst was reused in guaiacol $\mathrm{HDO}$ at $350{ }^{\circ} \mathrm{C}$ under 55 bar after rinsing it with diethyl ether [54]. The results were very promising showing that in three consecutive experiments more than $99 \%$ conversion was achieved. On the other hand, $\mathrm{W}_{2} \mathrm{C} / \mathrm{CNF}$ gave lower activity exhibiting only $48 \%$ conversion after three consecutive experiments. $\mathrm{Mo}_{2} \mathrm{C} / \mathrm{CNF}$ catalyst suffered from irreversible coking during three consecutive $\mathrm{HDO}$ experiments of guaiacol at $300{ }^{\circ} \mathrm{C}$ under 40 bar [56]. The reuse of $\mathrm{Ni} / \mathrm{SiO}_{2}-\mathrm{ZrO}_{2}$ was investigated in guaiacol $\mathrm{HDO}$ at $300{ }^{\circ} \mathrm{C}$ under 50 bar hydrogen [62]. The results showed that in four consecutive experiments the conversion decreased as follows: $100 \%, 91 \%, 90 \%$ and $87 \%$ indicating minor catalyst deactivation.

The use of $\mathrm{Pt} / \mathrm{C}$ is favorable in HDO of phenolic compounds in order to avoid coke formation [57]. Successful recycling was demonstrated in 4-propylphenol HDO over Pt on active carbon giving more than $99 \%$ yield of propylcyclohexane in three consecutive experiments at $280{ }^{\circ} \mathrm{C}$ under 40 bar hydrogen [57]. The results revealed also that no sintering occurred. Recycling of noble metal supported catalysts in guaiacol HDO was done in three consecutive experiments, with catalyst washing with acetone and reduction at $200{ }^{\circ} \mathrm{C}$ in between. The results showed minor deactivation of $\mathrm{Ru} / \mathrm{C}$ and $\mathrm{Pd} /$ silica alumina [49]. It was confirmed that especially in HDO of eugenol the catalyst was poisoned by strongly adsorbed products causing also a brownish colour of the product.

In bio-oil HDO over noble metal catalysts supported on active carbon at $300{ }^{\circ} \mathrm{C}$ under $30 \mathrm{bar}$ hydrogen, the catalyst deactivation was intensive during reuse [30]. It was also concluded that $\mathrm{Ru} / \mathrm{C}$ deactivated mainly via fouling and blocking of active sites, whereas activity loss of $\mathrm{Pt} / \mathrm{C}$ was attributed to extensive char deposition on the catalyst surface.

\subsubsection{Time-on Stream Behavior in HDO of Model Compounds}

Time-on-stream behavior during $\mathrm{HDO}$ of cresol over $\mathrm{MoO}_{3}$ catalyst at $320{ }^{\circ} \mathrm{C}$ at atmospheric pressure showed catalyst deactivation. When the catalyst was regenerated at $400{ }^{\circ} \mathrm{C}$ via calcination, its original activity was restored, however, after each $24 \mathrm{~h}$ a repeated regeneration was required [36]. Promising results have been obtained in $\mathrm{HDO}$ of phenyl acetate over $\mathrm{Pt} / \mathrm{Al}_{2} \mathrm{O}_{3}$ at $325^{\circ} \mathrm{C}$ under 5 bar hydrogen. After $25 \mathrm{~h}$ time-on-stream a stable period of $40 \mathrm{~h}$ with constant activity followed [61]. Phenol formation was rapid from phenyl acetate, whereas the consecutive benzene formation was rather slow. Only minor catalyst deactivation was also observed in HDO of m-cresol, anisole, dimethoxybenzene and guaiacol mixture at $280^{\circ} \mathrm{C}$ under 1.5 bar pressure over $\mathrm{Mo}_{2} \mathrm{C}$ catalyst giving mostly toluene and benzene as products (Figure 18) [42]. On the other hand, the most rapid deactivation of $\mathrm{Mo}_{2} \mathrm{C} / \mathrm{ZrO}_{2}$ as a function of time on stream was observed in $\mathrm{HDO}$ of guaiacol at $350{ }^{\circ} \mathrm{C}$ under 60 bar hydrogen, followed by anisole and phenol showing clearly that compounds bearing two oxygen atoms caused the most intensive deactivation (Figure 18) [39]. Prominent catalyst deactivation observed in guaiacol HDO can partially be explained by a strongly bound phenate mode of guaiacol by double anchoring to the catalyst surface covering a large part of active sites [80]. Catalyst deactivation occurred also in HDO of anisole and guaiacol over Pt-Sn/CNF/Inconel as a funbction of time on stream (Figure 19) [48]. In addition, in the HDO of anisole, less water is formed than, for example, in phenol HDO. At higher temperature catalyst stability is improved in the presence of smaller amounts of adsorbed water. Catalyst deactivation in guaiacol HDO was also more intensive than in HDO of anisole over Pt-Sn/CNF catalyst at $400{ }^{\circ} \mathrm{C}$ under atmospheric pressure (Figure 20) i.e., conditions favoring deactivation [48]. Guaiacol is overall more reactive than anisole at $400{ }^{\circ} \mathrm{C}$, thus more prominent catalyst 
deactivation in HDO of guaiacol compared to anisole is mainly seen from the product distribution. For anisole, the main product was benzene, whereas it was anisole for HDO of guaiacol.

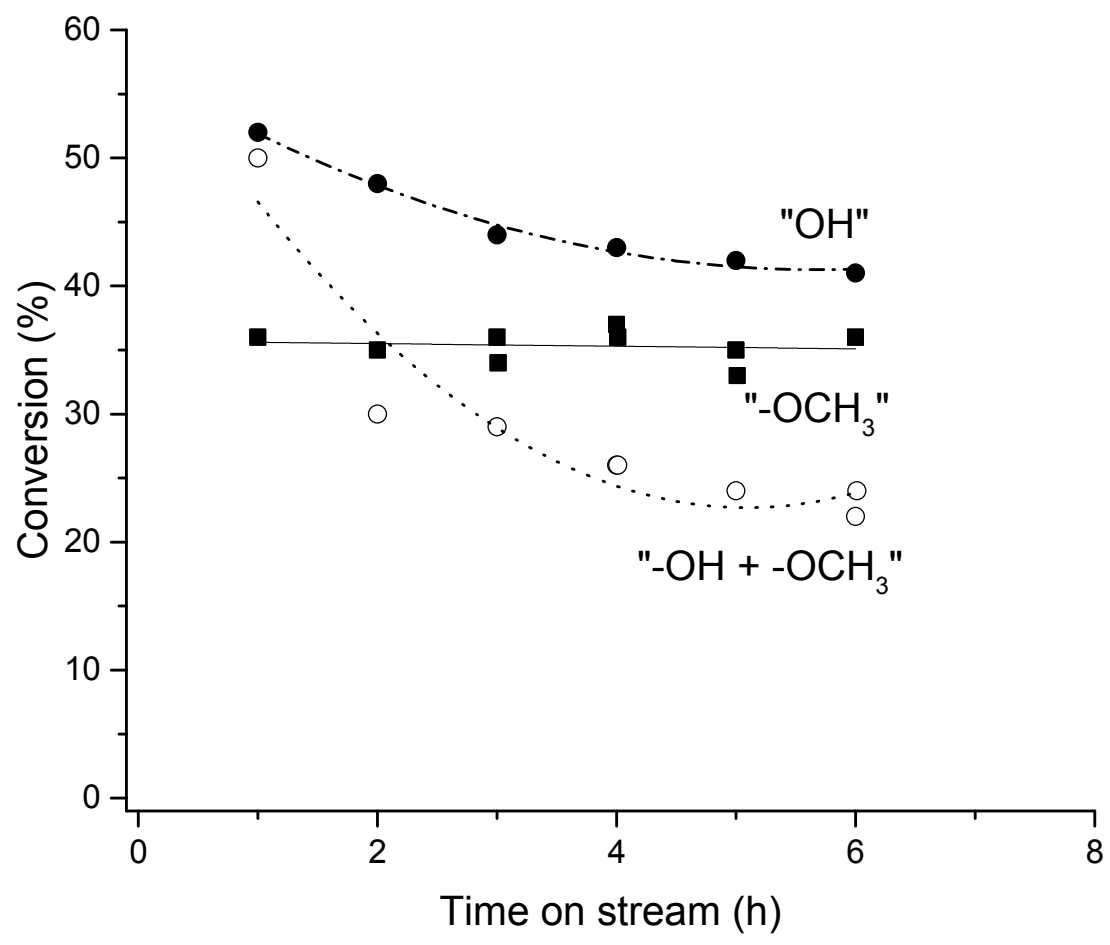

Figure 18. Conversion of guaiacol, anisole and phenol in their single feed $\mathrm{HDO}$ at $350{ }^{\circ} \mathrm{C}$ under 60 bar

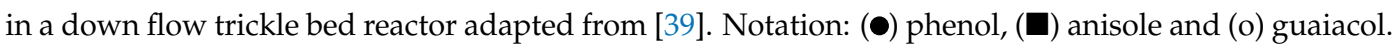
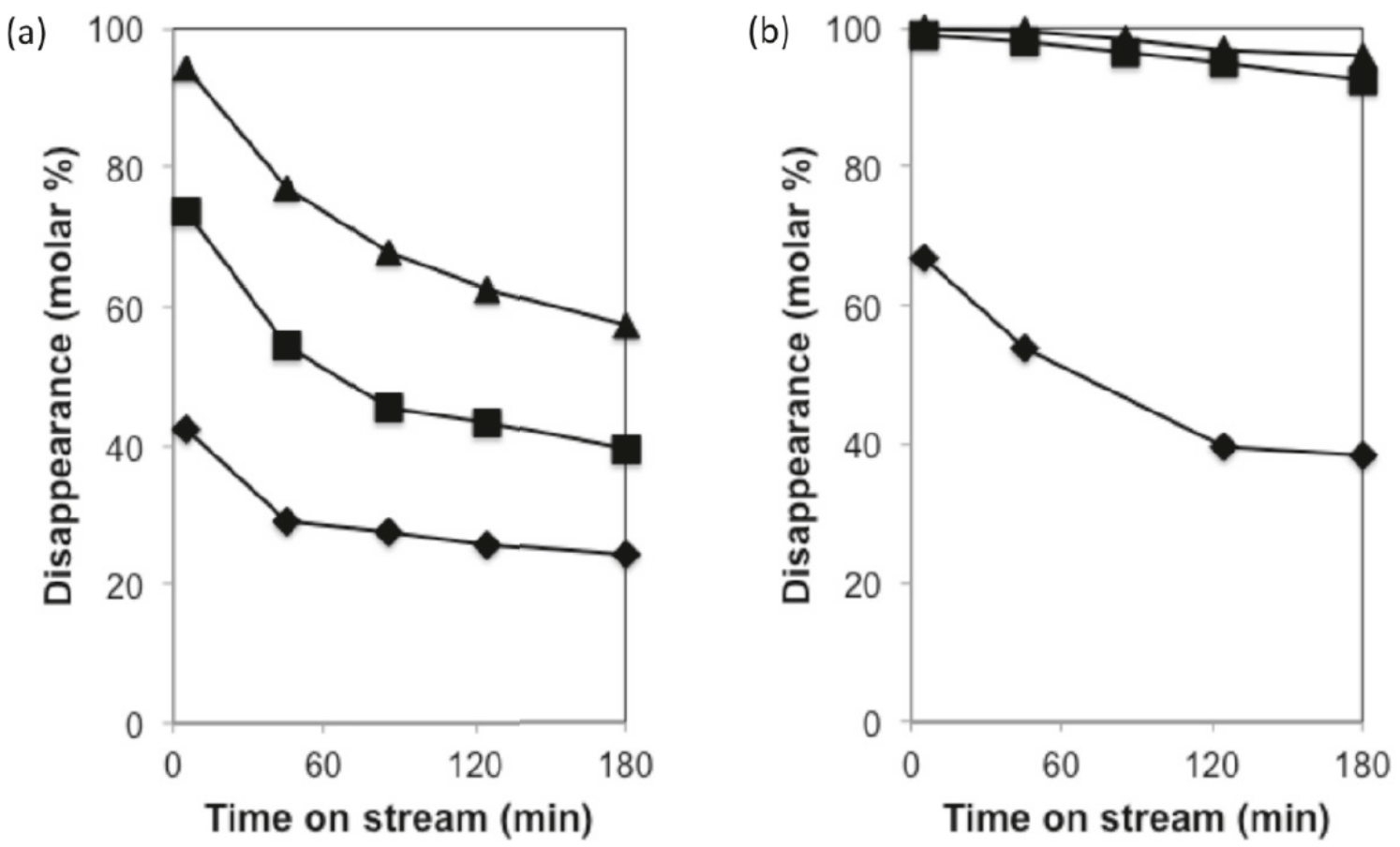

Figure 19. Continuous hydrodeoxygenation of (a) anisole and (b) guaiacol at $400{ }^{\circ} \mathrm{C}$ under atmospheric pressure over Pt-Sn/CNF/Inconel catalyst [48]. 


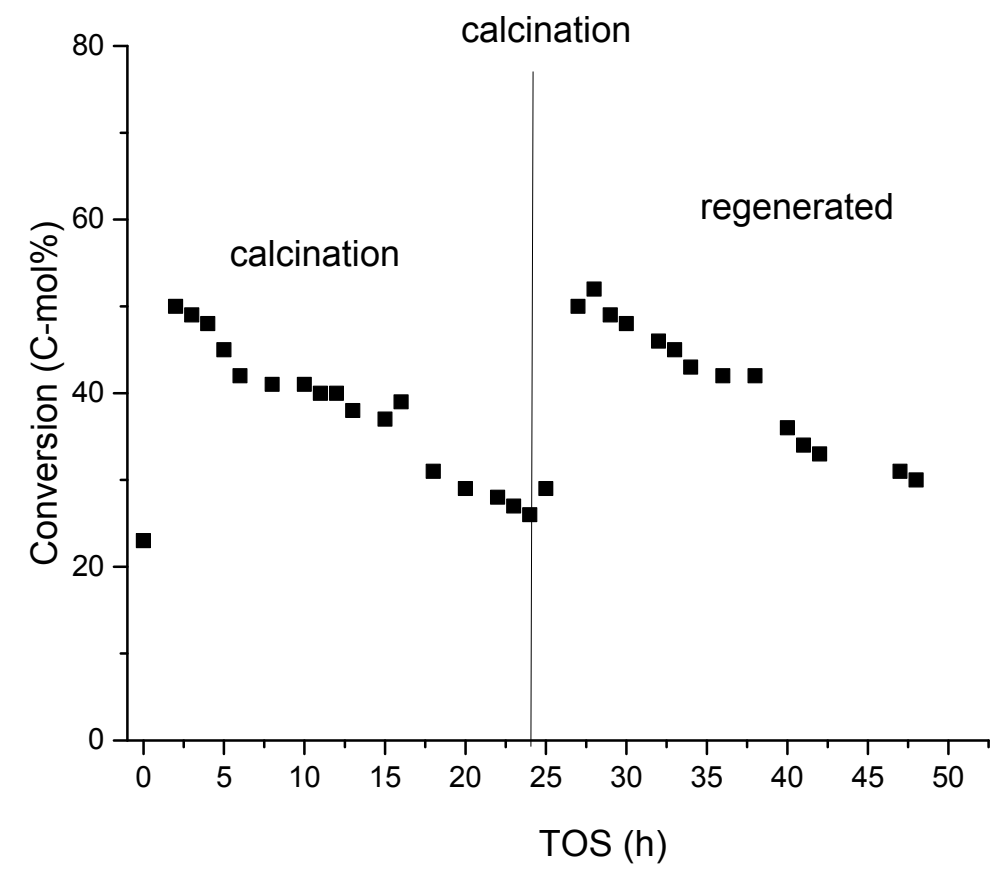

Figure 20. Conversion of $\mathrm{m}$-cresol as a function of time on stream at $320^{\circ} \mathrm{C}$ under 1 bar over $\mathrm{MoO}_{3}$ catalyst. Regeneration of the catalyst was performed at $400{ }^{\circ} \mathrm{C}$ in oxygen for $3 \mathrm{~h}$ adapted from [36].

Catalyst regeneration has also been investigated in continuous operation [36]. Typically, the catalyst is calcined in air at $400{ }^{\circ} \mathrm{C}$ in order to avoid sintering of metal-like particles, as it was the case in HDO of m-cresol at $320^{\circ} \mathrm{C}$ under atmospheric pressure over $\mathrm{MoO}_{3}$ (Figure 21) [36]. The results showed clearly that already after $24 \mathrm{~h}$ TOS the catalyst activity declined from $50 \%$ conversion to $28 \%$ conversion and the intermittent calcination was required in order to keep the catalyst activity high enough.

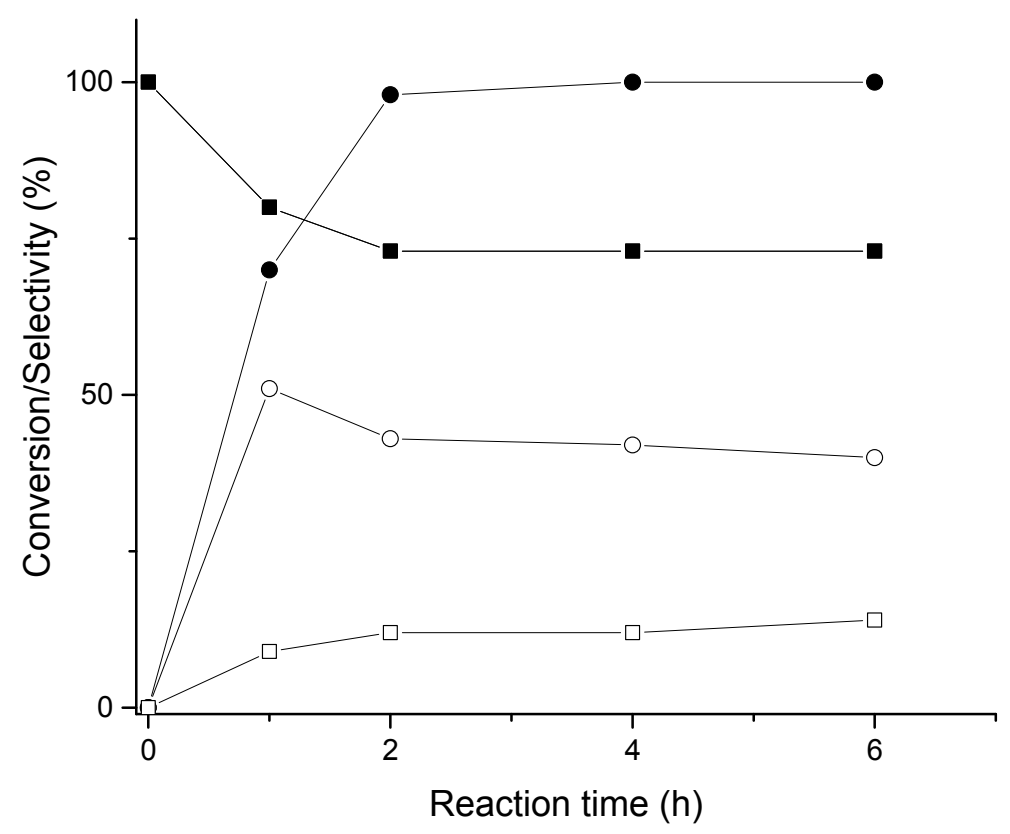

Figure 21. Results from $\mathrm{HDO}$ of guaiacol over $\mathrm{Mo}_{2} \mathrm{C} / \mathrm{CNF}$ catalyst at $350{ }^{\circ} \mathrm{C}$ under 55 bar hydrogen.

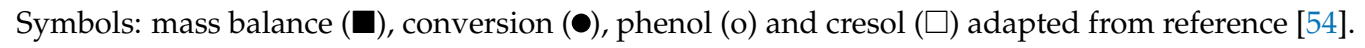




\subsubsection{Catalyst Selection in HDO of Phenolic Compounds}

Precious metal catalysts have some advantages during HDO of phenolic compounds being highly active at low pressures and temperatures and enabling use of smaller reactors and other economic benefits [61]. Metal-like carbides have also shown activity in HDO of phenolic compounds [56]. For nitride and carbide catalysts, neutral carbon and zirconia are preferred as supports in direct deoxygenation of guaiacol [46]. Hydrophobic carbons are also efficient supports for bio-oil HDO [78] deactivating only slightly in the presence of water during bio-oil HDO [55].

Hydrothermal stability of the catalysts is important during HDO of lignin derived phenolic compounds. It is known that $\mathrm{ZrO}_{2}$ exhibits hydrothermal stability, whereas alumina is unstable in the presence of water under hydrothermal conditions [81]. Nitrides have been more stable against sulfides in HDO of guaiacol in a continuous operation [58]. Transition metal carbides, nitrides and phosphides require demanding preparation conditions and exhibit poor stability in $\mathrm{HDO}$ of phenolic compounds [37]. Performing $\mathrm{HDO}$ at higher temperature enhances stability of $\mathrm{MoO}_{3} / \mathrm{ZrO}_{2}$ due to lower amounts of water adsorbed on the catalyst surface [39].

\subsubsection{Coking during HDO of Model Compounds}

Possible reasons for catalyst deactivation during HDO of phenolic compounds are coking [34] and poisoning [47], in addition to a loss of active sites. In some cases minor sintering has been observed [31]. In guaiacol HDO over Pt/C slight catalyst deactivation occurred at $325{ }^{\circ} \mathrm{C}$ [31]. Coking can be explained by ring condensation favored by low pressure and high temperature [82], whereas aromatic hydrogenation is favored at lower temperature using high hydrogen pressure. Condensed ring products are more strongly adsorbed on the catalyst surface and can be desorbed only at higher temperatures [83]. Co-MCM-41 was used for HDO of guaiacol resulting in a quite rapid catalyst deactivation occurred at $400{ }^{\circ} \mathrm{C}$ under atmospheric conditions [34], as these conditions promoted extensive coking.

Coking during HDO is typically favored over catalysts having acidic supports, while for less acidic supports, such as zirconia and activated carbon, the catalysts retain their activity longer [58]. More intensive coking during $\mathrm{HDO}$ of guaiacol at $300^{\circ} \mathrm{C}$ was observed for $\mathrm{Ru} / \mathrm{C}$ compared to $\mathrm{Pt} / \mathrm{C}$ [31]. Catalyst coking has been also investigated in HDO of guaiacol and anisole [50]. Confirming that reactant nature has an effect on coking in particular more coke has been formed from guaiacol than anisole on Ni-based catalysts at relatively high temperatures, between $350-400{ }^{\circ} \mathrm{C}$ [50]. Coke formation was confirmed in guaiacol $\mathrm{HDO}$ at $400{ }^{\circ} \mathrm{C}$ under atmospheric pressure over $\mathrm{Co} / \mathrm{Al}-\mathrm{MCM}-41$ catalyst by TGA [34]. Furthermore, it was stated that the catalyst regeneration at $4500^{\circ} \mathrm{C}$ was not able to release all coke. From TEM images it was found that coke is located on both on acidic sites and close to Co-particles [34] leading to conclusion that coke formation depends not only on acidity, but also on the presence of metal sites [34].

Analysis of coke deposited on the spent catalyst used in $\mathrm{HDO}$ of guaiacol at $300{ }^{\circ} \mathrm{C}$ under atmospheric pressure was performed using thermogravimetry and GC-MS [31]. The TGA results revealed that more coke was desorbed from $\mathrm{Ru} / \mathrm{C}$ compared to $\mathrm{Pt} / \mathrm{C}$. Furthermore, linked ring structures such as biphenyl, aromatic compounds, e.g., benzene, and condensed rings including naphthalene and 1-methylnaphtalene were found after extraction of adsorbed species by dichloromethane not being present in the liquid product. It was additionally concluded that there was no sintering of $\mathrm{Ru} / \mathrm{C}$ under $\mathrm{HDO}$ conditions, while minor sintering of $\mathrm{Pt} / \mathrm{C}$ was observed.

\subsubsection{Deactivation Due to Strong Adsorption on the Catalyst Surface}

Deactivation studies of different supports, such as alumina and silica have been performed by adsorption of different model molecules (phenol, anisole, guaiacol) on these supports and desorbing them at different temperatures [79]. Based on IR-studies interaction mechanisms of these molecules at higher temperatures have been proposed. The results revealed that anisole is demethylated at 
higher temperature, whereas guaiacol is bound via two oxygen atoms on Al-sites. The amounts of adsorbed species on $\mathrm{SiO}_{2}$ were much lower than those recorded for $\mathrm{Al}_{2} \mathrm{O}_{3}$ in the case of phenol and anisole. Even if for guaiacol adsorption quantitative data were not achieved, it was concluded that its interaction with supports was clearly stronger than for phenol and anisole. Strong adsorption of reactants or other molecules during eugenol hydrodeoxygenation has been proposed to cause catalyst deactivation [49]. In eugenol HDO incomplete carbon balance at $250{ }^{\circ} \mathrm{C}$ under 30 bar hydrogen in hexadecane over noble metal catalysts supported was ascribed strong adsorption of the products on the catalyst surface [49].

Adsorption strength of guaiacol and anisole was investigated using pulse experiments at $400{ }^{\circ} \mathrm{C}$ by adsorbing these molecules on Pt-Sn/CNF catalyst [48]. It was confirmed that guaiacol is more strongly adsorbed than anisole. Furthermore, it was also stated that guaiacol and its HDO-product, catechol with two oxygen atoms, are more strongly adsorbed on the catalyst surface than their single functionalized counterparts, e.g., anisole and phenol [48].

\subsubsection{Poisons in Bio-Oil Causing Catalyst Deactivation}

Hydrodeoxygenation (HDO) is an important treatment method for bio-oils which have low stability and heating value as described above. Due to a complex structure of bio-oil and presence of possible catalyst poisons [47] and water, its HDO is, however, demanding. Bio-oils stemming from hemicellulose and cellulose contain also acetic acid and furfural, which have been used as co-feed in $\mathrm{HDO}$ of guaiacol [56]. Co-feed including also $\mathrm{H}_{2} \mathrm{O}, \mathrm{CO}_{2}$ and $\mathrm{O}_{2}$ has been used in $\mathrm{HDO}$ of guaiacol $[33,59]$.

The effect of several poisons, such as chlorine, sulfur and potassium was investigated in HDO of guaiacol and 1-octanol over $\mathrm{Ni} / \mathrm{ZrO}_{2}$ catalyst in a trickle bed reactor at $250{ }^{\circ} \mathrm{C}$ under 100 bar hydrogen [47]. In these experiments, the catalyst was deactivated with 1-octanethiol, 1-chlorooctane, $\mathrm{KCl}$ or $\mathrm{KNO}_{3}$. When using potassium salts a stoichiometric amount of salt compared to nickel was used. The results revealed that with sulfur present in the catalyst, the latter retained its activity during more than $4 \mathrm{~h}$ which was followed by a dramatic activity drop almost to zero. Effect of chlorine poisoning was more rapid decreasing the catalyst activity immediately after the start of the chlorine feed. On the other hand, a potassium poisoned catalyst exhibited high activity in guaiacol conversion, even if its deoxygenation activities towards guaiacol were $3 \%$ and $18 \%$ for respectively $\mathrm{KCl}$ and $\mathrm{KNO}_{3}$ in comparison with the not poisoned catalyst displaying $66 \%$ deoxygenation degree of guaiacol. It was also noteworthy that chlorine and potassium poisoning was reversible and chloride was found in the liquid product. Sulfur poisoning inhibited both hydrogenation of the aromatic ring in guaiacol as well as subsequent deoxygenation reactions over $\mathrm{Ni} / \mathrm{ZrO}_{2}$ catalyst at $250{ }^{\circ} \mathrm{C}$ under 100 bar hydrogen, whereas potassium poisoned mainly deoxygenation sites. Chlorine poisoning decreased both hydrogenation and deoxygenation activity of $\mathrm{Ni} / \mathrm{ZrO}_{2}$ catalyst.

The presence of acetic acid and furfural was investigated in $\mathrm{HDO}$ of guaiacol over $\mathrm{Mo}_{2} \mathrm{C} / \mathrm{CNF}$ catalyst in dodecane at $300^{\circ} \mathrm{C}$ under 40 bar hydrogen [56]. The results showed that both acetic acid and furfural were converted to a large extent, whereas guaiacol conversion was only $6 \%$ after $4 \mathrm{~h}$. The main products were phenol and catechol, while without furfural and acetic acid catechol formation was much lower. Catalyst stability was investigated during $\mathrm{HDO}$ of $\mathrm{m}$-cresol with $\mathrm{Mo}_{2} \mathrm{C}$ using co-feeds of $\mathrm{H}_{2} \mathrm{O}, \mathrm{CO}_{2}$ and $\mathrm{O}_{2}$ [59]. The results revealed that especially toluene formation rate was retarded with adsorption of oxygen on metal like sites catalyzing HDO reaction. In the gas phase HDO of $\mathrm{m}$-cresol-anisole, dimethoxybenzene and guaiacol mixture the experimental observations could be correlated with the bond dissociation energies showing that the most prominent products were toluene and benzene at $280^{\circ} \mathrm{C}$ over $\mathrm{Mo}_{2} \mathrm{C}$ catalysts. This catalyst was completely inactive for hydrogenation of the products. It was stated [59] that $\mathrm{CO}$ and water, which are typically present in pyrolysis vapor, inhibit hydrogenation of the aromatic ring.

Co-feeding $\mathrm{CO}$ and $\mathrm{CO}_{2}$ has been also investigated in $\mathrm{HDO}$ of guaiacol [33]. Direct hydrodeoxygenation of phenolic compounds was achieved over $\mathrm{Mo}_{2} \mathrm{C}$ catalyst without ring 
hydrogenation which was also confirmed by co-feed of water and CO. In guaiacol HDO in the presence of $\mathrm{CO}, \mathrm{CO}_{2}$ and water over $\mathrm{Fe} / \mathrm{SiO}_{2}$ catalyst at $400{ }^{\circ} \mathrm{C}$ under atmospheric pressure inhibition of guaiacol transformations to cresol was observed (Figure 22) [33]. In the vapor-phase anisole HDO, benzene was formed with high selectivity over metal-like carbides, $\mathrm{Mo}_{2} \mathrm{C}$ and $\mathrm{W}_{2} \mathrm{C}[43,44]$. It was, however, observed that with co-fed $\mathrm{CO}$ formation of benzene during anisole $\mathrm{HDO}$ was suppressed over $\mathrm{Mo}_{2} \mathrm{C}$ catalyst at $133{ }^{\circ} \mathrm{C}$ under atmospheric pressure [43]. Analogously in the presence of $\mathrm{CO}$-co-feeding during anisole $\mathrm{HDO}$ at $150{ }^{\circ} \mathrm{C}$ over $\mathrm{Mo}_{2} \mathrm{C}$ under atmospheric pressure benzene formation was suppressed and completely recovered after $\mathrm{CO}-\mathrm{co}-f e e d$ was stopped [44]. $\mathrm{Pt} / \mathrm{C}$ is active for water gas shift reaction forming carbon dioxide during HDO [84].

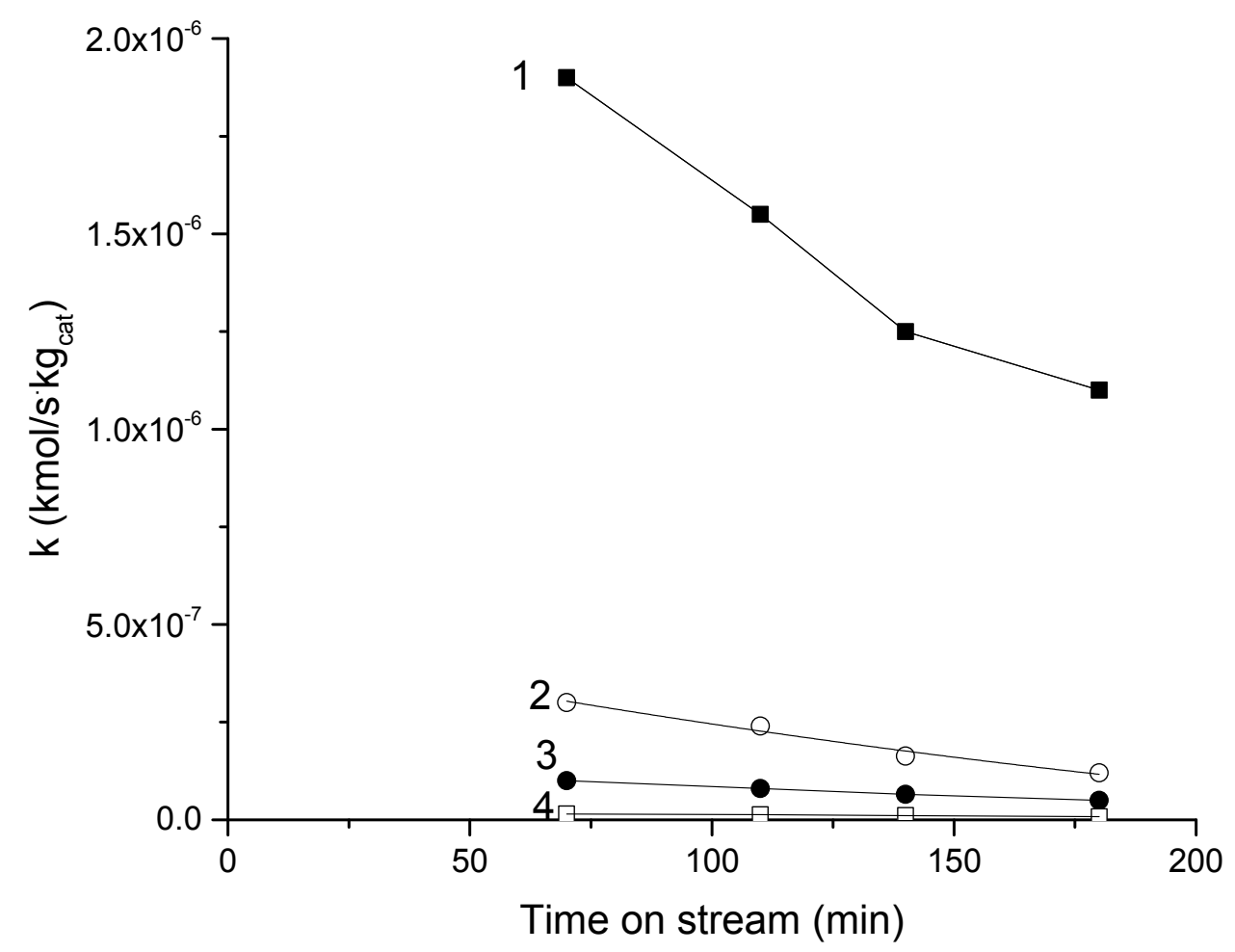

Figure 22. Decrease of the kinetic constants as a function of time on stream in the HDO of guaiacol at $400{ }^{\circ} \mathrm{C}$ under 1 bar over $\mathrm{Fe} / \mathrm{SiO}_{2}$ adapted from ref. [33]. The reaction mixture contained also $50 \% \mathrm{H}_{2}, 5 \% \mathrm{CO}_{2}, 2.5 \% \mathrm{CO}$ and $2.5 \% \mathrm{H}_{2} \mathrm{O}$. Notation: (1) guaiacol to products, line fitting: $=2.85 \cdot 10^{-6} e^{-4.61 \cdot 10^{-3} x}$, (2) guaiacol to cresol, line fitting : $y=4.93 \cdot 10^{-7} e^{-7.29 \cdot 10^{-3} x}$, (3) phenol to benzene, line fitting: $y=1.37 \cdot 10^{-7} e^{-4.85 \cdot 10^{-3} x}$, and (4) cresol to toluene, line fitting: $y=2.81 \cdot 10^{-8} e^{-5.03 \cdot 10^{-3} x}$.

\subsubsection{Carbon Balance during HDO of Model Compounds}

Mass balance in HDO of phenolic model compounds has often been reported to be below $100 \%[25,31,54]$. One example is guaiacol $\mathrm{HDO}$ over $\mathrm{Mo}_{2} \mathrm{C} / \mathrm{CNF}$ and $\mathrm{W}_{2} \mathrm{C} / \mathrm{CNF}$ catalysts (Figure 12) [54], where the authors also stated that the mass balance increased with increasing reaction temperature. A relatively high mass balance closure above $90 \%$ was achieved at $375{ }^{\circ} \mathrm{C}$ under 55 bar hydrogen [54]. Analogously to the work of Jongerius et al., mass balances vary in the range of 70-98\% in guaiacol $\mathrm{HDO}$ at $300{ }^{\circ} \mathrm{C}$ under 40 bar using $\mathrm{Mo}_{2} \mathrm{C} / \mathrm{CNF}$ catalysts (Figure 21). It also pointed out that the mass balances contained only the liquid phase and coke from the catalyst surface omitting the gaseous products [56]. Clearly coking [56] and release of products into the gas phase decrease the mass balance calculated on the basis of the liquid phase products. In HDO of guaiacol the highest carbon recovery in the liquid phase over noble metals supported on carbon was ca. $70 \%$ obtained at $300{ }^{\circ} \mathrm{C}$ [31]. Especially the ring opening reaction at high temperatures leads to formation of more 
gaseous products [18]. On the other hand, total carbon yields varied in the range of $95-98 \%$ in the HDO of different phenolic compounds at $300-350{ }^{\circ} \mathrm{C}$ over $\mathrm{MoO}_{3}$ catalyst under atmospheric pressure [36].

Solid products are also formed during HDO of phenolic compounds and lignin [2,25,62]. Polymerization, occurring especially for vanillin, is intensive, decreasing the carbon balance [25], for example, in vanillin $\mathrm{HDO}$ at $100{ }^{\circ} \mathrm{C}$ under 30 bar hydrogen over $\mathrm{Mo}_{2} \mathrm{C} / \mathrm{AC}$ catalyst. As a result mass balances in the range of $65-70 \%$ were reported. It was concluded by Zhang et al. [62] that the mass losses are caused by formation of coke and polymers as well as formation of volatile gaseous products. In addition large amounts of char were formed being in the range of $9-19 \%$ in the HDO of pyrolysis oil over Ni-supported catalysts at $300{ }^{\circ} \mathrm{C}$ under 30 bar hydrogen [4]. Noteworthy is that formation of a solid residue in lignin HDO decreased with increasing reaction temperature indicating that at higher temperature unwanted reactions of phenolic products are retarded [2].

Formation of gaseous products is typically enhanced at higher temperatures [31,34], while at lower temperatures less gases were formed [43]. For example, in the temperature range of $147-247^{\circ} \mathrm{C}$ no gaseous $\mathrm{C} 2-\mathrm{C} 5$ products were observed in vapor phase $\mathrm{HDO}$ of anisole on $\mathrm{Mo}_{2} \mathrm{C}$ and the main product was benzene formed by $\mathrm{C}-\mathrm{O}$ bond cleavage [43]. In addition, low gas generation during HDO was observed at $250{ }^{\circ} \mathrm{C}$ under 80 bar hydrogen over various Ni catalysts [35]. At elevated temperature, $350{ }^{\circ} \mathrm{C}$, both char and gas formation from HDO of miscanthus bio-oil was enhanced when HDO was performed over Pd/C catalyst under 30 bar of hydrogen [28]. Under these conditions char and gas yields vary in the ranges of $16 \%$ and $19-36 \%$, respectively depending on the reaction time in the range of 30-60 $\mathrm{min}$ [28]. The liquid yields, composed of light and heavy oil fractions were the highest, above $80 \%$, when $\mathrm{HDO}$ of bio-oil was performed over Pd/C catalyst between $250-300{ }^{\circ} \mathrm{C}$ [28].

Formation of gaseous products depends also on the type of active metal in the catalyst [31]. For noble metal catalysts the amounts of gaseous products formed during guaiacol HDO increased in the following order: $\mathrm{Pd} / \mathrm{C}<\mathrm{Ru} / \mathrm{C}<\mathrm{Rh} / \mathrm{C}<\mathrm{Pt} / \mathrm{C}$ [31]. A substantial amount of gaseous products, $50 \%$, was formed in $\mathrm{HDO}$ of guaiacol at $400{ }^{\circ} \mathrm{C}$ under atmospheric pressure over NiCo-Al-MCM-41 catalysts [34]. Methane formation was very extensive during HDO of guaiacol over Co/Al-MCM-41 at $400{ }^{\circ} \mathrm{C}$ under atmospheric pressure and it increased with increasing ratio of catalyst weight to feed rate [34]. The gas phase product amount was was the highest with Ni/Al-MCM-41, being 78\%, whereas it was the lowest (30\%) for Co-MCM-41 [34]. The main gaseous product yield in the HDO of bio-oil over supported Ni-catalysts at $300{ }^{\circ} \mathrm{C}$ under 30 bar hydrogen was $\mathrm{CO}$ being in the range of $88-95 \%$ from the gaseous products, followed by methane varying in the range of $2-7.1 \%$ [4]. It was also possible to obtain a few $\%$ of propane, ethyne and ethane [4]. Only minor amounts of methane were formed over supported Ni-catalysts in the HDO of guaiacol under 7.9 bar hydrogen in the temperature range of $350-450{ }^{\circ} \mathrm{C}$, whereas coking was rather high under these conditions over Ni-catalysts being in the range of 3-8 $\mathrm{wt} \%$ from the total products [50]. Analogously, in the HDO of pyrolysis bio-oil from yellow polar over Ni supported catalysts at $300^{\circ} \mathrm{C}$ under 30 bar of hydrogen, formation of gaseous products was significant over $\mathrm{Ni}$ supported catalysts varying in the range of $6.6-27 \%$ depending on the support type [4]. On the other hand, low methanation degree was achieved over $\mathrm{MoO}_{3} / \mathrm{ZrO}_{2}$ at $320^{\circ} \mathrm{C}$ under atmospheric pressure in anisole HDO showing clearly its carbon efficiency [51].

\subsubsection{Modelling of Deactivation for HDO of Model Compounds}

Modelling of deactivation along with kinetic modelling was performed [33] for HDO of guaiacol over $\mathrm{Fe} / \mathrm{SiO}_{2}$ catalyst [33]. When the rate constants were plotted against time on stream it was noticed that the decrease of rate constants occurred similarly for HDO of phenol to benzene and cresol to toluene, whereas in guaiacol transalkylation to cresol the decline of the rate constant was more rapid (Figure 22) [33]. Thus, it was concluded that inhibition of guaiacol to cresol transformations may happen on different sites compared to HDO reactions. 


\section{Conclusions}

Hydrodeoxygenation of bio-oils, lignin and their model compounds has been intensively investigated in the recent years. The main findings in this area are summarized in the current work. Several model molecules have been used in HDO of bio-oil including single, double or triple oxygenated phenolic compounds. Several reaction networks based on kinetic results have been proposed especially for guaiacol HDO. The main parameters affecting activity and product distribution are temperature and pressure, type of a catalytically active metal, nature of the support and its acidity. Two main pathways during HDO are either ring hydrogenation followed by deoxygenation at high pressure and temperature below $300{ }^{\circ} \mathrm{C}$, as well as deoxygenation at elevated temperatures, when hydrogenation is thermodynamically suppressed.

The degree of deoxygenation is important in order to increase the energy density and heating value of the products. Typically, guaiacol is deoxygenated at elevated temperatures or under very high pressures at temperatures below $350{ }^{\circ} \mathrm{C}$ affording $\mathrm{HDO}$ yields between $60-80 \%$. One exception in guaiacol $\mathrm{HDO}$ is $\mathrm{Ni} / \mathrm{SiO}_{2}-\mathrm{ZrO}_{2}$ giving $97 \%$ cyclohexane at $300{ }^{\circ} \mathrm{C}$ under 50 bar. In addition to cyclohexane, also cyclopentanone is formed, especially over Pt. These results can be explained theoretically at a DFT level, confirming the reactivity of phenolic compounds decreases with an increasing number of oxygen atoms. Moreover, thermodynamically the hydroxyl group connected to benzene is more difficult to cleave compared to a methoxy group. HDO of real bio-oils was also successfully demonstrated over various Ni-and Pd-supported catalysts. Unstable compounds, such as furfural, acetic acid and levoglucosan were also transformed to more stable ketones and esters. In addition, high HDO activity was obtained for lignin itself, especially over Ni/H-BEA catalyst.

Catalyst deactivation studies revealed that main reason for catalytic activity decline during HDO of phenolic compounds is coking in addition to reactant polymerization. Interestingly higher mass balance closures exceeding $90 \%$ for guaiacol at $375{ }^{\circ} \mathrm{C}$ could be achieved at very high temperatures, due to suppression of oxygen compounds, such as phenol over $\mathrm{Mo}_{2} \mathrm{C} / \mathrm{CNF}$. Catalyst poisoning was systematically investigated showing irreversible bulk poisoning of the catalyst with sulphur, whereas chlorine poisoning was reversible. Hydrothermal stability of the catalyst is of crucial importance and suitable candidates are active carbon and $\mathrm{ZrO}_{2}$, whereas alumina and metal carbides exhibit lower stability under catalytically relevant conditions. The HDO of phenolic compounds is challenging and requires optimization of different parameters, such as temperature, pressure and the catalyst per se in order to maximize the liquid product yield and produce desired compounds with high enough heating value and RON number.

In addition, further research efforts are still needed to diminish hydrogen consumption and provide high carbon efficiency.

Author Contributions: P.M-A designed the review, collected references and wrote the first draft. D.Yu.M. revised the text and contributed to the final paper.

Conflicts of Interest: The authors declare no conflict of interest.

\section{References}

1. Hussin, M.H.; Rahim, A.A.; Ibrahim, M.N.M.; Brosse, N. Physicochemical characterization of alkaline and ethanol organosolv lignins from palm oil (Elaeis guineensis) fronds as phenol substitutes for green material applications. Ind. Crops Prod. 2013, 49, 23-32. [CrossRef]

2. Kasakov, S.; Shi, H.; Camaioni, D.M.; Zhao, C.; Baráth, E.; Jentys, A.; Lercher, J.A. Reductive deconstruction of organosolv lignin catalyzed by zeolite supported nickel nanoparticles. Green Chem. 2015, 17, 5079-5090. [CrossRef]

3. Koranyi, T.I.; Hensen, E.J.M. Preparative aspects of supported $\mathrm{Ni}_{2} \mathrm{P}$ catalysts for reductive upgrading of technical lignin to aromatics. Catal. Lett. 2017, 147, 1722-1731. [CrossRef]

4. Oh, S.; Choi, H.S.; Choi, I.G.; Choi, J.W. Evaluation of hydrodeoxygenation reactivity of pyrolysis bio-oil with various Ni-based catalysts for improvement of fuel properties. RSC Adv. 2017, 7, 15116-15126. [CrossRef] 
5. Wang, H.; Male, J.; Wang, Y. Recent advances in hydrotreating of pyrolysis bio-oil and its oxygen-containing model compounds. ACS Catal. 2013, 3, 1047-1070. [CrossRef]

6. Bu, Q.; Lei, H.; Zacher, A.H.; Wang, L.; Ren, S.; Liang, S.; Wei, Y.; Liu, Y.; Tang, J.; Zhang, Q.; et al. A review of catalytic hydrodeoxygenation of lignin-derived phenols from biomass pyrolysis. Bioresour. Technol. 2012, 124, 470-477. [CrossRef] [PubMed]

7. Cheng, F.; Brewer, C.E. Producing jet fuel from biomass lignin: Potential pathways to alkylbenzenes and cycloalkanes. Renew. Sustain. Energy Rev. 2017, 72, 673-722. [CrossRef]

8. He, Z.; Wang, X. Hydrodeoxygenation of model compounds and catalytic systems for pyrolysis biooils upgrading. Catal. Sustain. Energy 2013, 28-52. [CrossRef]

9. Lee, H.; Kim, Y.-M.; Lee, I.-G.; Jeom, J.-K.; Jung, S.-C.; Chung, J.D.; Choi, W.G.; Park, Y.-K. Recent advances in the catalytic hydrodeoxygenation of bio-oil. Korean J. Chem. Eng. 2016, 33, 3299-3315. [CrossRef]

10. Saidi, M.; Samimi, F.; Karimipourfard, D.; Nimmanwudipong, T.; Gates, B.C.; Rahimpour, M.R. Upgrading of lignin-derived bio-oils by catalytic hydrodeoxygenation. Energy Environ. Sci. 2014, 7, 103-129. [CrossRef]

11. Shafaghat, H.; Rezaei, P.S.; Mohd, W.; Wan Daud, A. Effective parameters on selective catalytic hydrodeoxygenation of phenolic compounds of pyrolysis bio-oil to high-value hydrocarbons. RSC Adv. 2015, 5, 103999-104042. [CrossRef]

12. Sullivan, M.M.; Chen, C.-J.; Bhan, A. Catalytic deoxygenation on transition metal carbide catalysts. Catal. Sci. Technol. 2016, 6, 602-616. [CrossRef]

13. Zacher, A.H.; Olarte, M.V.; Santosa, D.M.; Elliott, D.C.; Jones, S.B. A review and perspectives of recent bio-oil hydrotreating research. Green Chem. 2014, 16, 491-515. [CrossRef]

14. Wang, Y.; De, S.; Yan, N. Rational control of nano-scale metal-catalysts for biomass conversion. Chem. Commun. 2016, 52, 6210-6224. [CrossRef] [PubMed]

15. Mortensen, P.M.; Grundwaldt, J.-D.; Jensen, P.A.; Knudsen, K.G.; Jensen, A.D. A review of catalytic upgrading of bio-oil to engine fuels. Appl. Catal. A Gen. 2011, 407, 1-19. [CrossRef]

16. Chang, J.; Danuthai, T.; Dewiyanti, S.; Wang, C.; Borgna, A. Hydrodeoxygenation of guaiacol over carbon-supported metal catalysts. ChemCatChem 2013, 5, 3041-3049. [CrossRef]

17. Nie, L.; de Souza, P.M.; Noronha, F.B.; An, W.; Sooknoi, T.; Resasco, D.E. Selective conversion of m-cresol to toluene over bimetallic Ni-Fe catalysts. J. Mol. Catal. A Chem. 2014, 388-389, 47-55. [CrossRef]

18. Sun, J.; Karim, A.M.; Zhang, H.; Kovarik, L.; Li, X.S.; Hensley, A.J.; McEwen, J.-S.; Wang, Y. Carbon-supported bimetallic Pd-Fe catalysts for vapor-phase hydrodeoxygenation of guaiacol. J. Catal. 2013, 306, 47-57. [CrossRef]

19. Huang, X.; Atay, C.; Koranyi, T.I.; Boot, M.D.; Hensen, E.J.M. Role of Cu-Mg-Al mixed oxide catalysts in lignin depolymerization in supercritical ethanol. ACS Catal. 2015, 5, 7359-7370. [CrossRef]

20. Do, P.T.M.; Foster, A.J.; Chen, J.; Lobo, R.F. Bimetallic effects in the hydrodeoxygenation of meta-cresol on $\gamma-\mathrm{Al}_{2} \mathrm{O}_{3}$ supported Pt-Ni and Pt-Co catalysts. Green Chem. 2012, 14, 1388-1897. [CrossRef]

21. Parsell, T.H.; Owen, B.C.; Klein, I.; Jamell, T.M.; Marcum, C.L.; Haupert, L.J.; Amundson, L.M.; Kenttämaa, H.I.; Ribeiro, F.; Miller, J.T.; et al. Cleavage and hydrodeoxygenation (HDO) of C-O bonds relevant to lignin conversion using Pd/Zn synergistic catalysts. Chem. Sci. 2013, 4, 806-813. [CrossRef]

22. Gao, D.; Xiao, Y.; Varma, A. Guaiacol hydrodeoxygenation over platinum catalyst: Reaction pathways and kinetics. Ind. Eng. Chem. Res. 2015, 54, 10638-10644. [CrossRef]

23. Zanuttini, M.S.; Dalla Costa, B.O.; Querini, M.A.; Peralta, M.A. Hydrodeoxygenation of m-cresol with Pt supported over mild acid materials. Appl. Catal. A Gen. 2014, 482, 352-361. [CrossRef]

24. Zhu, X.; Lobban, L.L.; Mallinson, R.G.; Resasco, R.E. Bifunctional transalkylation and hydrodeoxygenation of anisole over a Pt/H-Beta catalyst. J. Catal. 2011, 281, 21-29. [CrossRef]

25. He, L.; Qin, Y.; Lou, H.; Chen, P. Highly dispersed molybdenum carbide nanoparticles supported on activated carbon as an efficient catalyst for the hydrodeoxygenation of vanillin. RSC Adv. 2015, 5, 43141-43147. [CrossRef]

26. Yoon, J.S.; Lee, T.; Choi, J.-W.; Suh, D.J.; Lee, K.; Ha, J.-M.Y.; Choi, J. Layered MWW zeolite-supported Rh catalysts for the hydrodeoxygenation of lignin model compounds. Catal. Today 2017, 293-294, 142-150. [CrossRef]

27. Zhang, C.; Xing, J.; Song, L.; Xin, H.; Lin, S.; Xing, L.; Li, X. Aqueous-phase hydrodeoxygenation of lignin monomer eugenol: Influence of $\mathrm{Si} / \mathrm{Al}$ ratio of HZSM-5 on catalytic performances. Catal. Today 2014, 234, 145-152. [CrossRef] 
28. Oh, S.; Hwang, H.; Choi, H.S.; Choi, J.W. Investigation of chemical modifications of micro-and macromolecules in bio-oil during hydrodeoxygenation with $\mathrm{Pd} / \mathrm{C}$ catalyst in supercritical ethanol. Chemosphere 2014, 117, 806-814. [CrossRef] [PubMed]

29. Jiang, H.; Yu, X.; Peng, X.; Zhang, H.; Nie, R.; Lu, X.; Zhou, D.; Xia, Q. Efficient aqueous hydrodeoxygenation of vanillin over mesoporous carbon-nitride modified Pd nanoparticles. RSC Adv. 2016, 6, 69045-69051. [CrossRef]

30. Oh, S.; Hwang, H.; Choi, H.S.; Choi, J.W. The effects of noble metal catalysts of the bio-oil quality during the hydrodeoxygenative upgrading process. Fuel 2015, 153, 535-543. [CrossRef]

31. Gao, D.; Schweitzer, C.; Hwang, H.T.; Varma, A. Conversion of guaiacol on noble metal catalysts: Reaction performance and deactivation studies. Ind. Eng. Chem. Res. 2014, 53, 18658-18667. [CrossRef]

32. Zhu, X.; Mallinson, R.G.; Resasco, D.E. Role of transalkylation reactions in the conversion of anisole over HZSM-5. Appl. Catal. A 2010, 379, 172-181. [CrossRef]

33. Olcese, R.N.; Francois, J.; Bettahar, M.M.; Petitjean, D.; Dufour, A. Hydrodeoxygenation of guaiacol, a surrogate of lignin pyrolysis vapors, over iron based catalysts: Kinetic and modelling of the lignin to aromatic integrated process. Energy Fuels 2013, 27, 975-984. [CrossRef]

34. Tran, N.T.T.; Uemuyra, Y.; Chowdhury, S.; Ramli, A. Vapor-phase hydrodeoxygenation of guaiacol on Al-MCM-41 supported Ni and Co catalysts. Appl. Catal. A Gen. 2016, 512, 93-100. [CrossRef]

35. Boscagli, C.; Raffelt, K.; Zevaco, T.A.; Olbrich, W.; Otto, T.N.; Sauer, J.; Grunwealdt, J.D. Mild hydrotreatment of the light fraction of fast-pyrolysis oil produced from straw over nickel-based catalysts. Biomater. Bioeng. 2015, 83, 525-538. [CrossRef]

36. Prasomsri, T.; Shetty, M.; Murugappan, K.; Roman Leshkov, Y. Insights into the catalytic activity and surface modification of $\mathrm{MoO}_{3}$ during the hydrodeoxygenation of lignin-derived model compounds into aromatic hydrocarbons under low hydrogen pressures. Energy Environ. Sci. 2014, 7, 2660-2669. [CrossRef]

37. Ghampson, I.T.; Sepuldeva, C.; Garcia, R.; Fierro, J.L.G.; Escalona, N. Carbon nanofiber-supported ReO catalysts for the hydrodeoxygenation of lignin-derived compounds. Catal. Sci. Technol. 2016, 6, 4356-4369. [CrossRef]

38. Sepuldeva, C.; Leiva, K.; Garcia, R.; Radovic, L.R.; Ghampson, I.T.; DeSisto, W.J.; Garcia Fierro, J.L.; Escalona, N. Hydrodeoxygenation of 2-methoxyphenol over $\mathrm{Mo}_{2} \mathrm{~N}$ catalysts supported on activated carbons. Catal. Today 2011, 172, 232-239.

39. Lodeng, R.; Ranga, C.; Rajkhowa, T.; Alexiadis, V.I.; Bjorkan, H.; Chytil, S.; Svenum, I.H.; Walmsley, J.; Thybaut, J.W. Hydrodeoxygenation of phenolics on liquid phase over supported $\mathrm{MoO}_{3}$ and carburized analogous. Biomass Convers. Biorefin. 2017, 1-17. [CrossRef]

40. Shafaghat, H.; Rezaei, P.S.; Wan Daud, W.M.A. Catalytic hydrodeoxygenation of simulated phenolic bio-oil to cycloalkane and aromatic hydrocarbons over bifunctional metal/acid catalysts of Ni/Beta, Fe/H-Beta and NiFe/HBeta. J. Ind. Eng. Chem. 2016, 35, 268-276. [CrossRef]

41. Nimmanwudipong, T.; Aydin, C.; Lu, J.; Runnebaum, R.C.; Brodwater, K.C.; Browning, N.D.; Block, D.E.; Gates, B.C. Selective hydrodeoxygenation of guaiacol catalyzed by platinum supported on magnesium oxide. Catal. Lett. 2012, 142, 1190-1196. [CrossRef]

42. Chen, C.-J.; Lee, W.-S.; Bhan, A. $\mathrm{Mo}_{2} \mathrm{C}$ catalyzed vapor phase hydrodeoxygenation of lignin-derived phenolic compound mixtures to aromatics under ambient pressure. Appl. Catal. A Gen. 2016, 510, 42-48. [CrossRef]

43. Lee, W.-S.; Wang, Z.; Wu, R.J.; Bhan, A. Selective vapor-phase hydrodeoxygenation of anisole to benzene on molybdenum carbide catalysts. J. Catal. 2014, 319, 44-53. [CrossRef]

44. Lu, Q.; Chen, C.-J.; Luc, W.; Chen, J.G.; Bhan, A.; Jiao, F. Ordered mesoporous metal carbides with enhanced anisole hydrodeoxygenation selectivity. ACS Catal. 2016, 6, 3506-3514. [CrossRef]

45. Lee, C.R.; Yoon, J.S.; Suh, Y.W.; Choi, J.-W.; Ha, J.-M.; Suh, D.J.; Park, Y.-K. Catalytic roles of metals and supports on hydrodeoxygenation of lignin monomer guaiacol. Catal. Commun. 2012, 17, 54-58. [CrossRef]

46. Bui, V.N.; Laurenti, D.; Afanasiev, P.; Geantet, C. Hydrodeoxygenation of guaiacol with CoMo catalysts. Part I: Promoting effect of cobalt on HDO selectivity and activity. Appl. Catal. B Environ. 2011, 101, 239-245. [CrossRef]

47. Mortensen, P.M.; Grunwaldt, J.-D.; Jensen, P.A.; Knudsen, G.; Jensen, A.D. Stability and resistance of nickel catalysts for hydrodeoxygenation: Carbon deposition and effects of sulfur, potassium, and chlorine in the feed. Catal. Sci. Technol. 2014, 4, 3672-3686. [CrossRef] 
48. Gonzalez-Borja, M.A.; Resasco, D.E. Anisole and guaiacol hydrodeoxygenation over monolithic Pt-Sn catalysts. Energy Fuels 2011, 45, 4155-4162. [CrossRef]

49. Deepa, A.K.; Dhepe, P.L. Function of metals and supports on the hydrodeoxygenation of phenolic compounds. ChemPlusChem 2014, 79, 1573-1583. [CrossRef]

50. Peters, J.E.; Carpenter, J.R.; Dayton, D.C. Anisole and guaiacol hydrodeoxygenation reaction pathway over selected catalysts. Energy Fuels 2015, 29, 909-916. [CrossRef]

51. Shetty, M.; Murugappan, K.; Green, W.H.; Roman-Leshkov, Y. Structural properties and reactivity trends of molybdenum oxide catalysts supported on zirconia for the hydrodeoxygenation of anisole. ASC Sustain. Chem. Eng. 2017, 5, 5293-5301. [CrossRef]

52. Yoon, J.S.; Lee, Y.; Yu, J.; Kim, Y.-A.; Park, E.D.; Choi, J.-W.; Ha, J.-M.; Suh, D.J.; Lee, H. Production of high carbon number hydrocarbon fuels from a lignin-derived-O-4 phenolic dimer, benzyl phenyl ether, via isomerization of ether to alcohols on high-surface-area silica-alumina aerogel catalyst. Appl. Catal. B Environ. 2013, 142-143, 668-676. [CrossRef]

53. Strassberger, Z.; Alberts, A.H.; Louwerse, M.J.; Tanase, S.; Rothenberg, G. Catalytic cleavage of lignin $\beta-\mathrm{O}-4$ link mimics using copper on alumina and magnesia-alumina. Green Chem. 2013, 15, 768-774. [CrossRef]

54. Jongerius, A.L.; Gosselink, R.W.; Djikstra, J.; Bitter, J.H.; Bruijnincx, P.C.-A.; Weckhuysen, B.M. Carbon nanofiber supported transition-metal carbide catalysts for the hydrodeoxygenation of guaiacol. ChemCatChem 2013, 5, 2964-2972. [CrossRef]

55. Echeandia, S.; Arias, P.L.; Barrio, V.L.; Pawelec, B.; Fierro, J.L.G. Synergy effect in the HDO of phenol over $\mathrm{Ni}-\mathrm{W}$ catalysts supported on active carbon: Effect of tungsten precursors. Appl. Catal. B 2010, 101, 1-12. [CrossRef]

56. Santillan-Jimenez, E.; Perdu, M.; Pace, R.; Morgan, T.; Crocker, M. Activated carbon, carbon nanofiber and carbon nanotube supported molybdenum carbide catalysts for the hydrodeoxygenation of guaiacol. Catalysts 2015, 5, 424-441. [CrossRef]

57. Ohta, H.; Kobayashi, H.; Hara, K.; Fukuoka, A. Hydrodeoxygenation of phenols as lignin models under acid-free conditions with carbon-supported platinum catalysts. Chem. Commun. 2011, 47, 12209-12211. [CrossRef] [PubMed]

58. Ghampson, T.; Sepuldeva, C.; Garcia, R.; Radovic, L.R.; Garcia Fierro, J.L.; DeSisto, W.J.; Escalona, N. Hydrodeoxygenation of guaiacol over carbon-supported molybdenum nitride catalysts: Effects of nitriding and support properties. Appl. Catal. A Gen. 2012, 439-440, 111-124. [CrossRef]

59. Chen, C.-J.; Bhan, A. $\mathrm{Mo}_{2} \mathrm{C}$ modification by $\mathrm{CO}_{2}, \mathrm{H}_{2} \mathrm{O}$, and $\mathrm{O}_{2}$ : Effect of oxygen content and oxygen source on rates and selectivity of m-cresol hydrodeoxygenation. ACS Catal. 2017, 7, 1113-1122. [CrossRef]

60. Zhu, Z.; Tan, H.; Wang, J.; Yu, S.; Zhou, K. Hydrodeoxygenation of vanillin as a bio-oil model over carbonaceous microspheres-supported Pd catalysts in the aqueous phase and Pickering emulsions. Green Chem. 2014, 16, 2636-2643. [CrossRef]

61. Gonzalez, C.; Marin, P.; Diez, F.V.; Ordonez, S. Gas-phase hydrodeoxygenation of benzaldehyde, benzyl alcohol, phenyl acetate, and anisole over precious metal catalysts. Ind. Eng. Chem. Res. 2016, 55, 2319-2327. [CrossRef]

62. Zhang, X.; Zhang, Q.; Wang, T.; Ma, T.; Yu, Y.; Chen, L. Hydrodeoxygenation of lignin-derived phenolic compounds to hydrocarbons over $\mathrm{Ni} / \mathrm{SiO}_{2}-\mathrm{ZrO}_{2}$ catalysts. Bioresour. Technol. 2013, 134, 73-80. [CrossRef] [PubMed]

63. Liu, X.; Xu, L.; Xu, G.; Jia, W.; Ma, Y.; Zhang, Y. Selective hydrodeoxygenaiton of lignin-derived phenols to cyclohexanols or cyclohexanes over magnetic CoNx@NC catalysts under mild conditions. ASC Catal. 2016, $6,7611-7620$.

64. Gutierrez, A.; Turpeinen, E.-M.; Viljava, T.-R.; Krause, O. Hydrodeoxygenation of model compounds on sulfided $\mathrm{CoMo} / \gamma \mathrm{Al}_{2} \mathrm{O}_{3}$ and $\mathrm{NiMo} / \gamma-\mathrm{Al}_{2} \mathrm{O}_{3}$ catalysts: Role of sulfur-containing groups in reaction networks. Catal. Today 2017, 285, 125-134. [CrossRef]

65. Viljava, T.-R.; Komulainen, S.; Selvam, T.; Krause, A.O.I. Stability of CoMo/ $\mathrm{Al}_{2} \mathrm{O}_{3}$ catalysts: Effect of $\mathrm{HDO}$ cycles on HDS. Stud. Surf. Sci. Catal. 1999, 127, 145-152.

66. Senol, O.I.; Viljava, T.-R.E.; Krause, A.O.I. Hydrodeoxygenation of methyl esters on sulphided $\mathrm{NiMo} / \mathrm{Al}_{2} \mathrm{O}_{3}$ and $\mathrm{CoMo} / \mathrm{Al}_{2} \mathrm{O}_{3}$ catalysts. Catal. Today 2005, 100, 331-335. [CrossRef]

67. Aho, A.; Kumar, N.; Eränen, K.; Salmi, T.; Hupa, M.; Murzin, D.Y. Catalytic pyrolysis of woody biomass in a fluidized bed reactor: Influence of zeolite structure. Fuel 2008, 87, 2493-2501. [CrossRef] 
68. Johansson, A.; Aaltonen, O.; Ylinen, P. Organosolv pulping-Methods and pulp properties. Biomass 1987, 13, 45-65. [CrossRef]

69. Mansouri, N.-E.E.; Salvado, J. Structural characterization of technical lignins for the production of adhesives: Application to lignosulfonate, kraft, soda-anthraquinone, organosolv and ethanol process lignins. Ind. Crops Prod. 2006, 24, 8-16. [CrossRef]

70. Boot, M.; Frijters, C.; Lujitern, C.; Somers, B.; Baert, R.; Donkerbroek, A.; Klein-Douwel, R.J.H.; Dam, N. Cyclic oxygenates: A new class of second-generation biofuels for diesel engines? Energy Fuels 2009, 23, 1808-1817. [CrossRef]

71. Lee, K.; Gu, G.H.; Mullen, C.A.; Boateng, A.A.; Vlachos, D.G. Guaiacol hydrodeoxygenation mechanism on $\mathrm{Pt}(111)$ : Insights from density functional theory and linear free energy relations. ChemSusChem 2015, 8, 315-322. [CrossRef] [PubMed]

72. Verma, A.M.; Kishore, N. DFT analyses of reaction pathways and temperature effects on various guaiacol conversion reactions in gas phase environment. Chem. Select 2016, 1, 6196-6205. [CrossRef]

73. Liu, C.; Zhang, Y.; Huang, Y.; Huang, X. Study of guaiacol pyrolysis mechanism based on density function theory. Fuel Process. Technol. 2014, 123, 159-165. [CrossRef]

74. Chiu, C.-C.; Genest, A.; Borgna, A.; Rösch, N. Hydrodeoxygenation of guaiacol over Ru (0001): A DFT study. ACS Catal. 2014, 4, 4178-4288. [CrossRef]

75. Lu, J.; Heyden, A. Theoretical study of the reaction mechanism of the hydrodeoxygenation of guaiacol over a $\mathrm{Ru}(0001)$ model surface. J. Catal. 2015, 321, 39-50. [CrossRef]

76. Wheeler, C.; Jhalani, A.; Klein, E.J.; Tummala, S.; Schmidt, L.D. The water-gas-shift reaction at short contact times. J. Catal. 2004, 223, 191-199. [CrossRef]

77. Gevert, B.S.; Otterstedt, J.-E.; Massoth, F.E. Kinetics of the HDO of methyl-substituted phenols. Appl. Catal. 1987, 31, 119-131. [CrossRef]

78. Prins, R.; Bussell, M.E. Metal phosphides: Preparation, characterization and catalytic reactivity. Catal. Lett. 2012, 142, 1413-1436. [CrossRef]

79. Popov, A.; Kondratieva, E.; Goupil, J.M.; Mariey, L.; Bazin, P.; Gilson, J.-P.; Travert, A.; Mauge, F. Bio-oils hydrodeoxygenation: Adsorption of phenolic molecules on oxidic catalyst supports. J. Phys. Chem. 2010, 114, 15661-15670. [CrossRef]

80. Badawi, M.; Paul, J.F.; Cristol, S.; Payen, E.; Romero, Y.; Richard, F.; Brunet, S.; Lambert, D.; Portier, X.; Popov, A.; et al. Effect of water on the stability of Mo and CoMo hydrodeoxygenation catalysts: A combined experimental and DFT study. J. Catal. 2011, 282, 155-164. [CrossRef]

81. Ravenelle, R.M.; Copeland, J.R.; Kim, W.G.; Crittenden, J.C.; Sievers, C. Structural changes of $\gamma-\mathrm{Al}_{2} \mathrm{O}_{3}-$ supported catalysts in hot liquid water. ACS Catal. 2011, 1, 552-561. [CrossRef]

82. Kent, J.A. Handbook of Industrial Chemistry and Biotechnology; Springer: New York, NY, USA, 2012; Volume 18.

83. Bartholomew, C.H. Mechanisms of deactivation. Appl. Catal. A Gen. 2001, 212, 17-60. [CrossRef]

84. Snytnikov, P.V.; Sobyanin, V.A.; Belyaev, V.D.; Tsyrulnikov, P.G.; Shitova, D.A. Selective oxidation of carbon monoxide in excess hydrogen over Pt-, Ru-, and Pd-supported catalsyts. Appl. Catal. A Gen. 2003, 239, 149-156. [CrossRef]

(c) 2017 by the authors. Licensee MDPI, Basel, Switzerland. This article is an open access article distributed under the terms and conditions of the Creative Commons Attribution (CC BY) license (http://creativecommons.org/licenses/by/4.0/). 